\title{
Anatomia funcional de Protothaca (Leukoma) pectorina (Lamarck) (Bivalvia, Veneridae)
}

\author{
Cordélia de Oliveira Castro Guerón ${ }^{1}$ \\ Walter Narchi ${ }^{2}$
}

\begin{abstract}
Functional anatomy of Protothaca (Leukoma) pectorina (Lamarck) (Bivalvia, Veneridae). Protothaca (Leukoma) pectorina (Lamarck, 1818) lives from the West Indies to Santa Catarina State, Brazil, in soft muddy beaches in quiet waters of protected bays with little amounts of suspended material. A study of the functional anatomy of $P$. pectorina and its ecological aspects were undertaken. The anatomy and functioning of the stomach and the mechanisms for selection of particles were observed. The siphons, ctenidia, labial palps and stomach were analised and related to the animal's natural environment. The siphons belong to type B (YONGE 1948), the ctenidia to type C (1a) (ATKINS 1937). The ctenidia are homorhabdic (RIDEwOOD 1903) and the stomach belongs to type V (PURCHON 1960).

KEY WORDS. Bivalvia, Veneridae, Protothaca pectorina, functional anatomy, Brazilian littoral
\end{abstract}

A família Veneridae compreende doze subfamílias e cinqüenta e quatro gêneros encontrados nos mares do mundo (KEEN 1969). O gênero Protothaca Dall, 1902, pertencente à subfamília Chioninae Frizell, 1936, está relativamente bem representado na costa ocidental das Américas com cinco subgêneros e dez espécies (KeEN 1971). No Brasil, apenas Protothaca (Leukoma) pectorina (Lamarck, 1818) foi encontrada viva. A espécie ocorre das Antilhas até o sul do Brasil (DALl 1902); PALMER (1927) registrou sua ocorrência no Golfo de Pavia (Venezuela) e Trinidad. ALTENA (1971) descreveu conchas encontradas no Suriname, GraHAM (1955) indicou sua procedência em Georgetown e LAMARCK (1818) descreveu-a de Caiena, Guiana Francesa. No Brasil, a espécie foi encontrada na Paraíba e em Pernambuco (FISCHER-PIETTE et al. 1970). OrBIGNY (1847) coletou a espécie em abundância na baía do Rio de Janeiro durante a maré baixa. MAURY (1925) citou seu aparecimento no litoral de São Paulo. LANGE DE MORRETES (1949) e GOFFERJÉ (1950) registraram a ocorrência da espécie no litoral do Paraná. Rios $(1985,1994)$ indicou seu aparecimento no Brasil até o litoral de Santa Catarina, que seria o limite sul da ocorrência da espécie.

Da família Veneridae muitos gêneros foram estudados sob o ponto de vista da anatomia e da anatomia funcional. JONES (1979) descreveu a anatomia de cinco espécies de Chioninae sendo que duas delas ocorrem no litoral brasileiro: Chione

1) Departamento de Zoologia, Universidade Santa Úrsula. Rua Fernando Ferrari 75 , Botafogo, 22231-040 Rio de Janeiro, Rio de Janeiro, Brasil.

2) Departamento de Zoologia, Instituto de Biociências, Universidade de São Paulo. Caixa Postal 11461, 05422-970 São Paulo, São Paulo, Brasil. Bolsista do CNPq. 
cancellata (Linné, 1767) e Chione paphia (Linné, 1767) com o intuito de demonstrar que os caracteres da anatomia das partes moles e conchas juntamente com o registro final podem proporcionar muitos indícios para a construção de uma classificação filogenética. NARCHI \& GABRIELI (1980) preocuparam-se com o estudo da anatomia funcional de Chione subrostrata (Lamarck, 1818).

O presente trabalho visa principalmente o estudo da anatomia funcional de Protothaca pectorina e seus aspectos ecológicos. Analisará até onde um caráter atua, se os fatores ambientais e o comportamento do animal poderiam se desenvolver, mudar suas estruturas ou adaptar-se às diferentes condições a que são submetidas, comparando-as com as de Anomalocardia brasiliana (Gmelin, 1791) e Chione subrostrata, Veneridae que ocorrem na mesma região da Praia do Cardo, Sepetiba, Estado do Rio de Janeiro.

\section{MATERIAL E MÉTODOS}

Protothaca pectorina ocorre no litoral brasileiro em baías e enseadas de águas calmas, vivendo geralmente enterradas em fundo lodoso (Fig. 1). O substrato, no entanto, pode apresentar camadas arenosas subjacentes com seixos, grande quantidade de valvas de conchas e, muitas vezes, carapaças de crustáceos onde os espécimes do bivalve podem ser encontrados. A distribuição de $P$. pectorina para o litoral brasileiro conforme os registros de Rios $(1970,1975,1985,1994)$ está evidenciada na figura 2. Esta espécie foi coletada no litoral do Rio de Janeiro, na Praia do Cardo, Sepetiba (22 $59^{\prime}$ 'S e $43^{\circ} 41^{\prime} \mathrm{W}$ ), perto da Ponta do Ipiranga e do Rio do Ponto (Fig. 3). Nas marés baixas, esta praia apresenta grandes extensões que permanecem descobertas. Isto facilitou o trabalho de coleta, feito manualmente, através de escavações, às vezes realizadas com o auxílio de uma pá. Foram encontrados exemplares vivos, distribuídos aleatoriamente por toda a região exposta da Praia, inclusive no substrato com conchas e seixos que dificultavam a escavação. Aí elas se encontravam como que jogadas pela maré alta. A maior concentração desta espécie localizou-se numa região ao norte da Praia do Cardo, onde há um afloramento de rochas dispostas obliquamente à zona da maré e que penetra mar adentro. Enterrados no lodo, a cerca de sete centímetros da superfície, entre as rochas, foram coletados vários espécimes vivos. Juntamente com esta espécie, por toda a praia, foi comum o encontro um grande número de conchas vivas de Anomalocardia brasiliana, enterradas a aproximadamente cinco centímetros de profundidade; em menor número ocorreram Tagelus plebeius (Lightfoot, 1786) que cavam a cerca de $15 \mathrm{~cm}$ da superfície. Foram encontrados também poucos exemplares de Lucina pectinata (Gmelin, 1791), Macoma constricta (Bruguière, 1792), Chione subrostrata e Mytella charruana (Orbigny, 1842). Além destes bivalves, foram coletados dois espécimes vivos de Tellina nitens C.B. Adams, 1845, valvas de conchas de Pholas campechiensis Gmelin, 1791 e de Divalinga quadrisulcata (Orbigny, 1842).

A coleta de material para estudo foi realizada mensalmente durante os anos de 1987, 1988, mais esparsamente em 1990 e no primeiro semestre de 1991. Em cada excursão foram coletados, em média, quinze espécimes de $P$. pectorina. Depois de coletados, os espécimes foram transportados em recipientes de isopor com pequena quantidade de água, areia do substrato e arejadores a pilha. Em dias de temperatura muito alta, as caixas de isopor foram colocadas dentro de outras do 


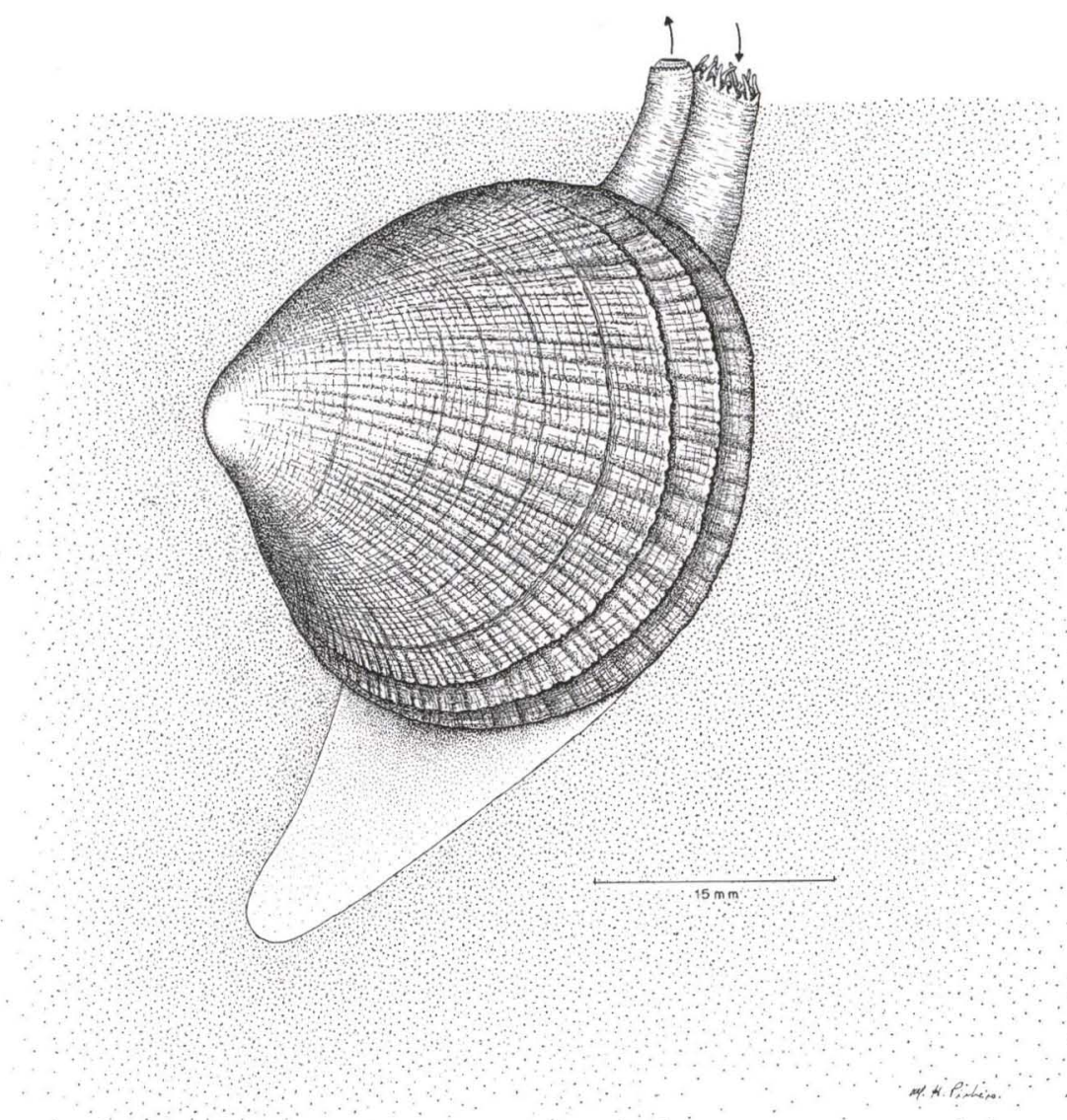

Fig. 1. Protothaca pectorina. Posição do animal no ambiente natural. As setas indicam a direção das correntes inalante e exalante.

mesmo material com algumas pedras de gelo para manter a temperatura abaixo da do ambiente. Com isso, as condições de sobrevivência dos moluscos durante o transporte tornaram-se mais seguras. Uma vez no laboratório, os animais foram colocados em aquários com água do mar. Foram realizadas a determinação do pH e medições de temperatura e salinidade, a fim de manter controladas as condições físico-químicas da água. Os aquários foram mantidos com a salinidade e temperatura iguais à do ambiente natural, respectivamente de 30 e $22^{\circ} \mathrm{C}$.

Foram utilizados animais vivos, bem como animais anestesiados com sulfato de magnésio a $7 \%$, animais fixados com álcool a $70 \%$ ou formol a $4 \%$.

$\mathrm{O}$ estudo da anatomia geral, assim como detalhes das estruturas dos palpos, ctenídios, canal alimentar e correntes ciliares foi efetuado com auxílio de microscópio estereoscópico com câmara lúcida acoplada. 


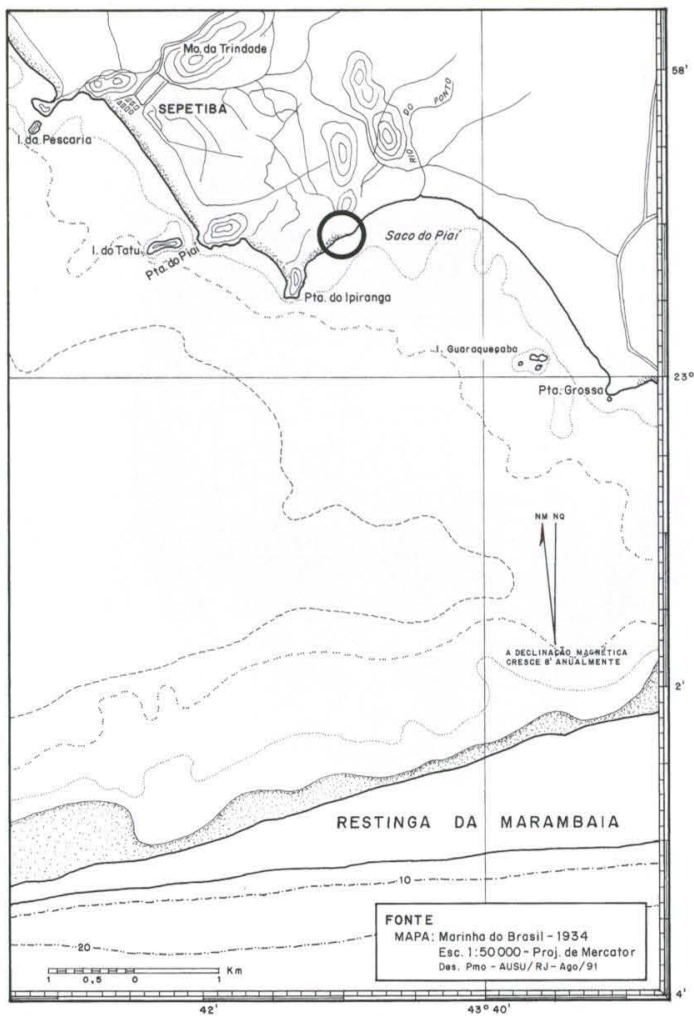

Fig. 2. Distribuição geográfica de Protothaca pectorina no litoral brasileiro. (๑) Locais de ocorrência da espécie.

Correntes ciliares das estruturas e órgãos da cavidade do manto foram visulalizadas com suspensão de carmim, Aquadag (grafite coloidal) e carborundum bem fino (120).

O estudo das correntes ciliares da superfície interna do manto foi realizado após a remoção de toda a massa visceral e dos ctenídios. Uma vez exposto, o manto do lado direito foi deixado em repouso na água do mar; em seguida, foram colocadas gotas de suspensão de carborundum ou carmim para a observação das correntes ciliares.

O estudo do canal alimentar de $P$. pectorina apresentou certa dificuldade pelo fato do sistema digestivo dessa espécie se encontrar completamente envolvido pelas gônadas e túbulos dos divertículos digestivos, cuja remoção necessitou muito cuidado para que não houvesse danos nas estruturas. Verificou-se que em animais fixados essa remoção era facilitada pois as estruturas se encontravam mais friáveis.

Cortes seriados de 8 a $10 \mu \mathrm{m}$ foram feitos em animais fixados em Bouin e incluídos em parafina. A coloração foi feita pelo processo tradicional da hemetoxilina e eosina.

Observações foram realizadas no local de coleta e os trabalhos de laboratório, no Departamento de Zoologia do Instituto de Biociências da Universidade de São Paulo e no Departamento de Zoologia da Universidade Santa Úrsula do Rio de Janeiro. 


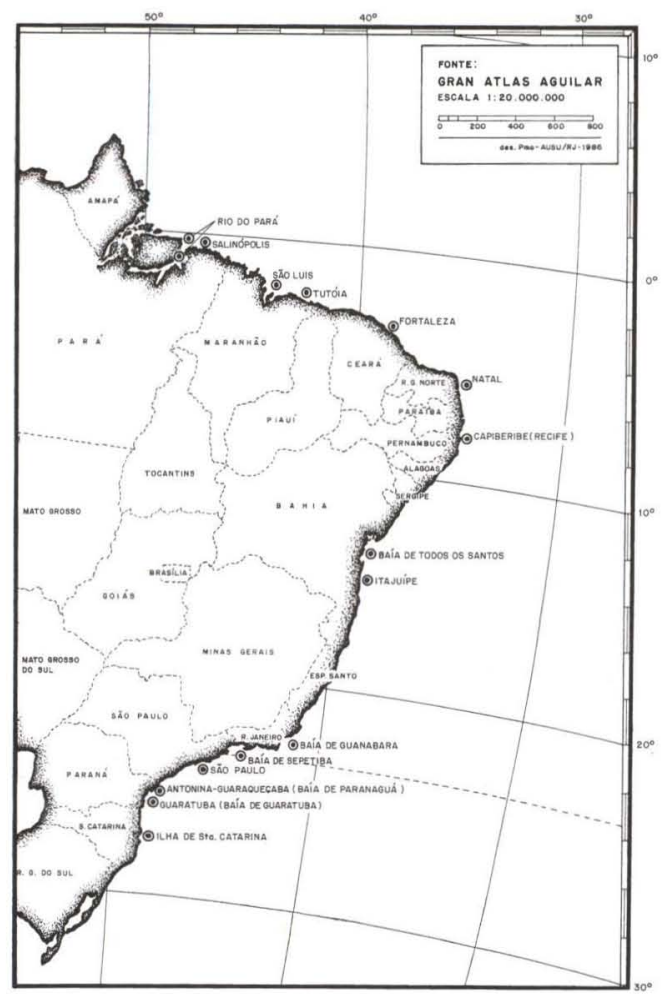

Fig. 3. Localização geográfica da região estudada. (O) local das coletas, Praia do Cardo.

\section{RESULTADOS}

\section{Valvas da concha}

A concha de $P$. pectorina (Fig. 4) é equivalve, inequilateral, oval trigonal, convexa com umbo inflado e bico quase mediano, arredondado, prosógiro e relativamente espessa e inflada. A escultura da concha é formada por linhas concêntricas muito finas, cruzadas por numerosas costelas radiais, resultando um aspecto cancelado. A lúnula, apenas delineada, é cordiforme, ligeiramente alongada, apresentando a mesma ornamentação típica da concha. Escudo não muito desenvolvido, sendo mais evidente na valva esquerda (Fig. 5). A área do ligamento opistodético tem sua porção externa alongada até mais ou menos um terço da região posterior da concha.

Em $P$. pectorina o perióstraco muito fino e transparente se encontra firmemente aderido às valvas. As valvas são de coloração branco-amarelada, cuja tonalidade pode variar. Na região posterior apresenta, contornando o escudo, manchas em zig-zag marrom-acinzentadas. Essas manchas ou são intensas ou não são presentes: algumas vezes não foram observadas em um número significativo de espécimes coletados. A coloração da concha pode escurecer à medida que o espécime cresce, pois é comum no seu perióstraco a aderência de partículas finíssimas do lodo do sedimento em que vive. 

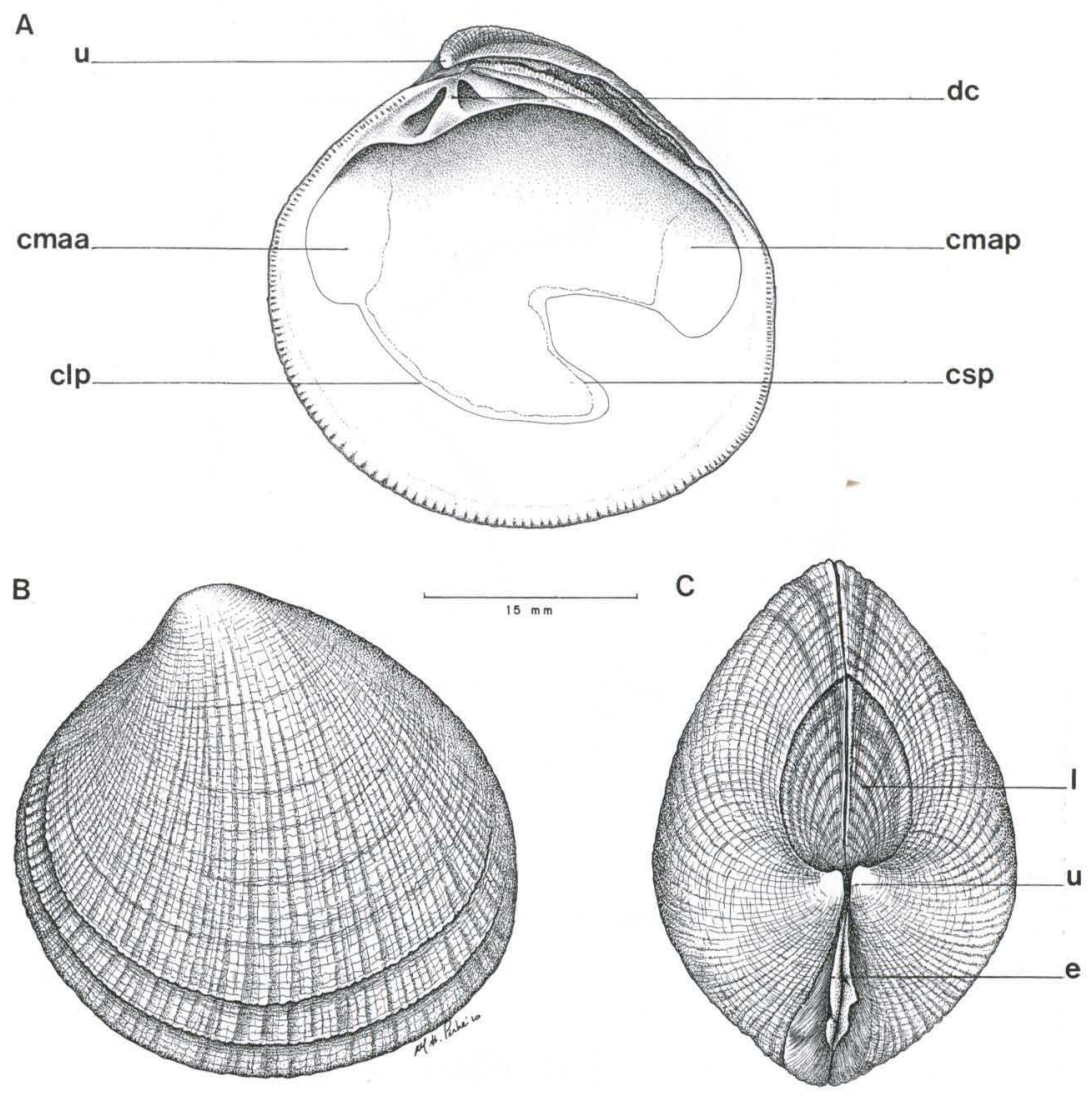

Fig. 4. Protothaca pectorina. (A) vista interna da valva direita: (clp) cicatriz da linha palial, (cmaa) cicatriz do músculo adutor anterior, (cmap) cicatriz do músculo adutor posterior, (csp), cicatriz do seio palial, (dc) dentes da charneira, (u) umbo; (B) vista externa da valva esquerda, evidenciando linhas de crescimento e ornamentação; (C) vista dorsal: (e) escudo, (I) lúnula, (u) umbo.

A região interna da concha é esbranquiçada, às vezes um pouco amarelada, com as cicatrizes da fixação dos músculos adutores, seio palial e linha palial bem delineados, de coloração amarelada e brilhante. A região marginal é normalmente amarelada, tornando-se de cor mais intensa próxima da margem crenulada. A margem ventral interna das valvas é crenulada e esta crenulação ocorre nas duas valvas da extremidade inferior por onde emergem os sifões até a altura do dente cardinal anterior. Estas margens possuem forma arredondada e seu contorno continua para a região anterior até a lúnula, sendo que nas proximidades da região posterior se flexiona ligeiramente formando uma linha reta até o limite do escudo, dando um aspecto levemente quadrangular à concha nesta região. 

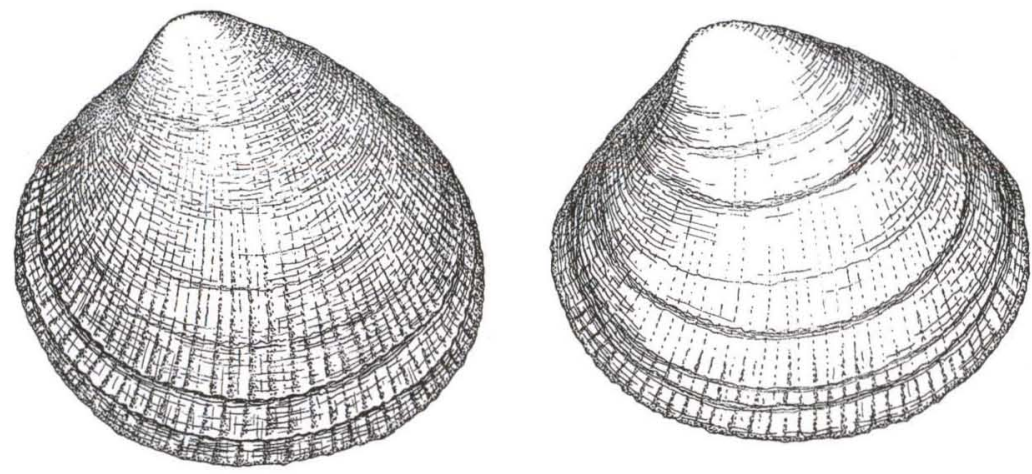

$20 \mathrm{~mm}$
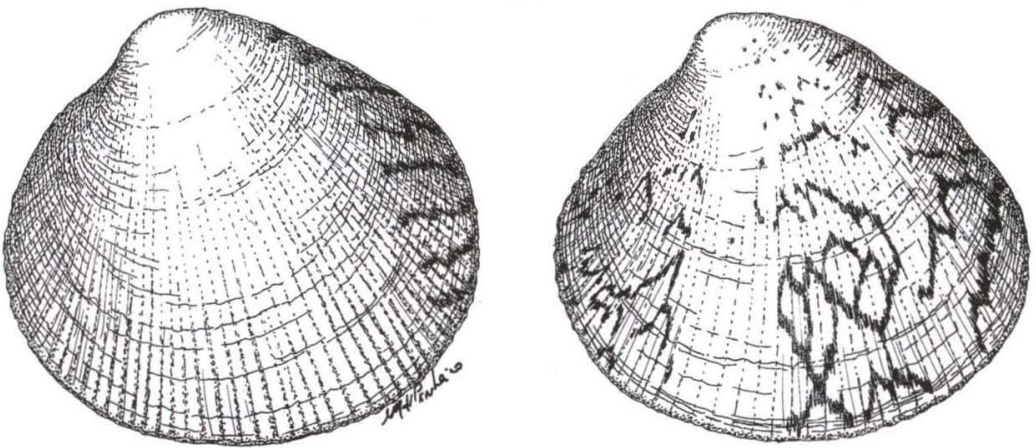

Fig. 5. Protothaca pectorina. Vista externa do lado esquerdo da concha, mostrando variação dos desenhos e das linhas radiais.

A cicatriz do músculo adutor anterior é oval, alongada, mais estreita em sua extremidade superior. Numa depressão abaixo da extremidade anterior da plataforma dental se localiza a cicatriz do músculo retrator anterior. A cicatriz do músculo adutor posterior é igualmente ovalada, porém mais larga e arredondada. Na extremidade postero-dorsal, se encontra a cicatriz do músculo retrator posterior do pé, como se fosse contínua com a impressão muscular do adutor posterior. A linha palial na região ventral é profunda, bem marcada e relativamente larga, situando-se paralelamente à margem ventral até a região posterior onde forma o seio palial; este é desenvolvido, agudo e voltado para a região anterior formando um ângulo de aproximadamente $45^{\circ} \mathrm{com}$ a linha marginal. A linha palial na porção dorsal compreende a região entre as extremidades dorsais das cicatrizes dos músculos retratores pediosos até a região umbonal, onde é pontilhada por diversas cicatrizes musculares diminutas.

A charneira de $P$. pectorina é forte e constituída por três dentes cardinais em cada valva (Fig. 6). Os dentes cardinais posterior e mediano da valva direita são sulcados e bem desenvolvidos; o anterior é pequeno e laminar. O dente cardinal anterior da valva esquerda, é laminar, triangular, pontudo e bem desenvolvido; o cardinal mediano é menor e sulcado; o posterior é laminar e muito pouco desenvolvido. 
O maior exemplar coletado durante a realização do presente trabalho mediu $4,2 \mathrm{~cm}$ de comprimento por $3,8 \mathrm{~cm}$ de altura e $2,7 \mathrm{~cm}$ de diâmetro, um pouco menor que o tamanho citado por Rios $(1985,1994)$. No decorrer desta pesquisa foram coletados alguns exemplares de $P$. pectorina mais espessos e mais inflados do que os comumente encontrados.

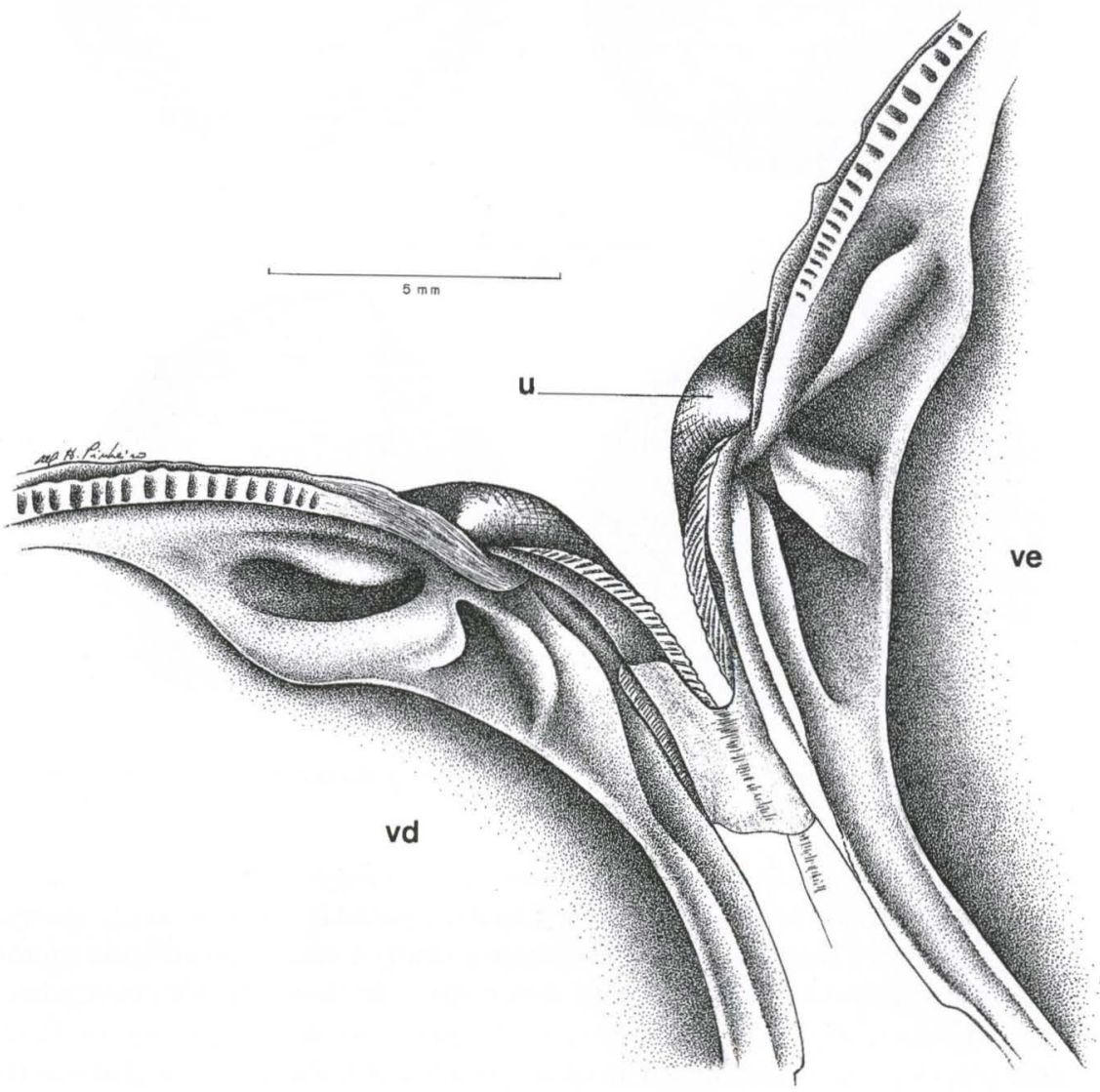

Fig. 6. Protothaca pectorina. Detalhe da charneira evidenciando os dentes cardinais das valvas direita e esquerda. (u) umbo, (vd) valva direita, (ve) valva esquerda.

\section{Sifões}

Em $P$. pectorina, os sifões (Fig. 7) são formados pelas dobras internas e pela superfície interna das dobras medianas das bordas do manto, o que indica pertencerem ao tipo B da classificação de YONGE $(1948,1982)$. Eles são unidos em quase toda a extensão e podem chegar a medir $2 \mathrm{~cm}$ em um animal de $4,2 \mathrm{~cm}$ de comprimento.

O sifão inalante é tubular com diâmetro maior que o exalante apresentando ao redor da abertura uma série de tentáculos. Existem 16 tentáculos digitiformes 
internos, relativamente grandes, originários da dobra interna das bordas do manto. São normalmente voltados para dentro da abertura sifonal, mais móveis e sensíveis, funcionando como seletores. Localizados externamente à coroa de tentáculos maiores, observa-se também um anel com 10 a 16 tentáculos pequenos, dando a impressão de estarem intercalados entre os maiores. Os tentáculos menores originam-se da superfície interna da dobra mediana das bordas do manto.

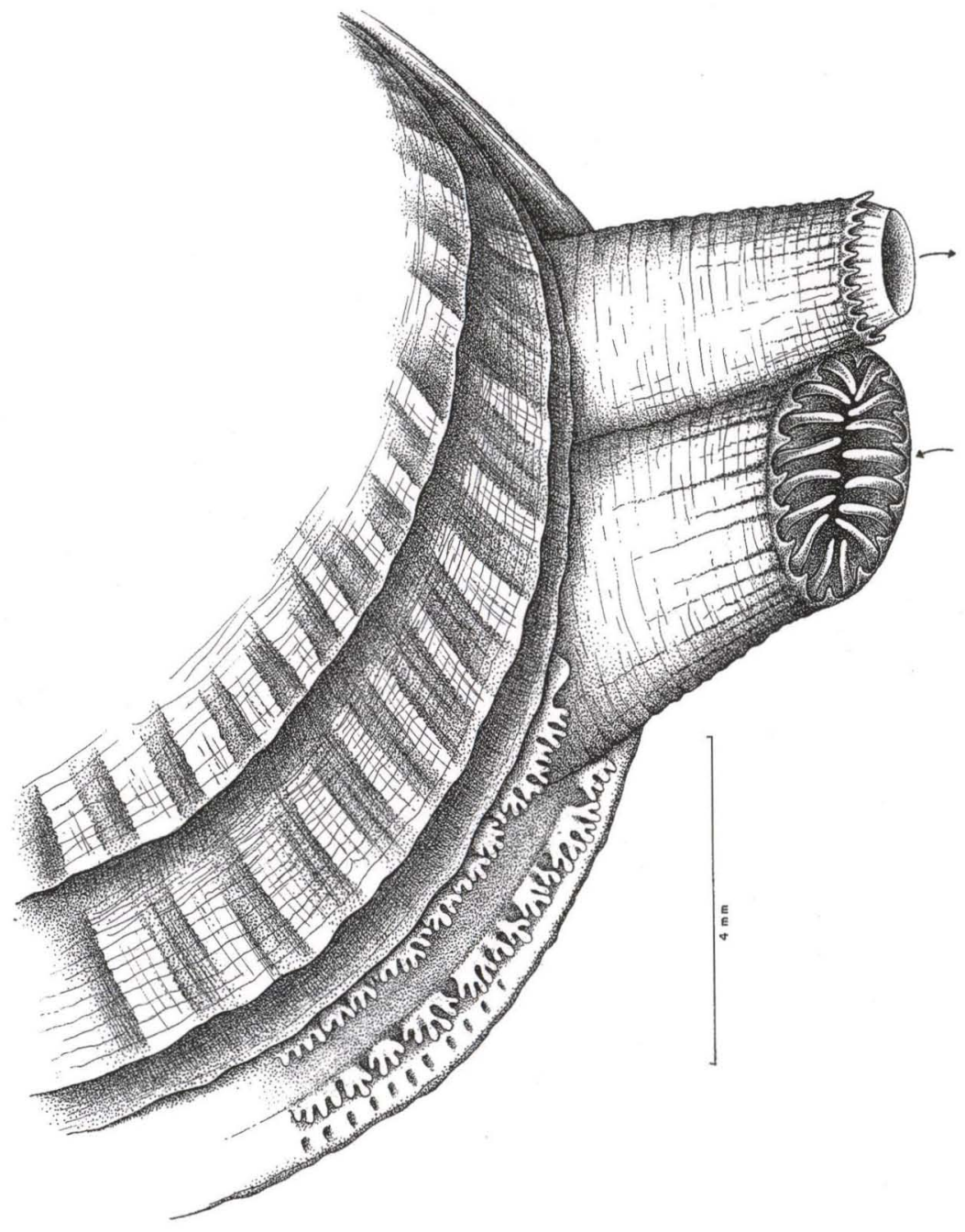

Fig. 7. Protothaca pectorina. Região posterior do espécime vivo evidenciando os sifões durante o processo de introdução de água na cavidade do manto; no sifão inalante existem tentáculos mais desenvolvidos voltados para dentro da abertura. A borda do manto apresenta-se com pregas e tentáculos. As setas indicam o sentido da corrente. 
O sifão exalante também é tubular e apresenta uma membrana cônica proveniente da dobra interna das bordas do manto, a qual confina e dirige a corrente de água. Esta membrana é circundada por um anel com cerca de 20 pequenos tentáculos digitiformes oriundos da dobra média da borda do manto.

Os sifões de $P$. pectorina são de cor amarelada com pigmentação cinza bastante escura. Na base dos tentáculos maiores do sifão inalante, a pigmentação se prolonga até aproximadamente à metade do sifão. Nas bases dos tentáculos menores e dos tentáculos do sifão exalante, aparece também uma pigmentação em linhas sinuosas que vão desta até o meio dos sifões. Internamente foram observadas também pequenas manchas brancas na região próxima à abertura dos sifões. Nas bordas proximais dos sifões ocorrem as membranas sifonais ou válvulas.

\section{Borda do Manto}

Em P. pectorina a margem do manto apresenta três dobras diferenciadas, e como nos Veneridae, há o aparecimento de uma dobra adicional, a quarta dobra.

A dobra externa (primeira dobra) é secretora, quase lisa, apresentando ligeiras ondulações.

A dobra mediana (segunda dobra) é sensorial, dupla, apresentando tentáculos (Fig. 8). A porção interna é bem desenvolvida, com pregas sinuosas e com cerca de seis a sete tentáculos para cada uma delas. Quando o animal está submerso os tentáculos das pregas da direita e da esquerda se entrelaçam. Esta posição mantida pelos tentáculos protege a cavidade do manto da entrada de partículas do lodo ou areia, onde os espécimes vivem. A dobra mediana externa (Fig. 8 A,B) é bem menos desenvolvida e levemente pregueada.

A dobra interna (terceira dobra), reduzida e lisa possui músculos radiais fixados na concha ao longo da linha palial; entre estes existem músculos circulares.

Em $P$. pectorina observou-se a quarta dobra do manto, restrita aos Veneridae, cuja atividade ciliar no decorrer de algumas horas acumulou partículas de carborundum ou areia, que foram envolvidas por muco formando um fio na borda do manto.

Na região posterior, logo após a abertura pediosa as dobras externa e mediana externa se continuam ao longo da extremidade da concha, passando sobre o músculo adutor posterior onde as dobras medianas em $P$. pectorina se fundem, continuando assim até o istmo do manto na região dorsal. A dobra mediana interna e a dobra interna se unem para formar os sifões, e anteriormente à abertura pediosa as dobras externa e mediana externa também se unem.

\section{Musculatura}

\section{Músculos adutores}

Os músculos adutores anterior e posterior de $P$. pectorina são semelhantes, e se encontram respectivamente inseridos na região anterior e posterior da valva da concha, logo abaixo da região da charneira (Fig. 9). O músculo adutor posterior é ligeiramente maior que o anterior, e sua secção mais arredondada. 

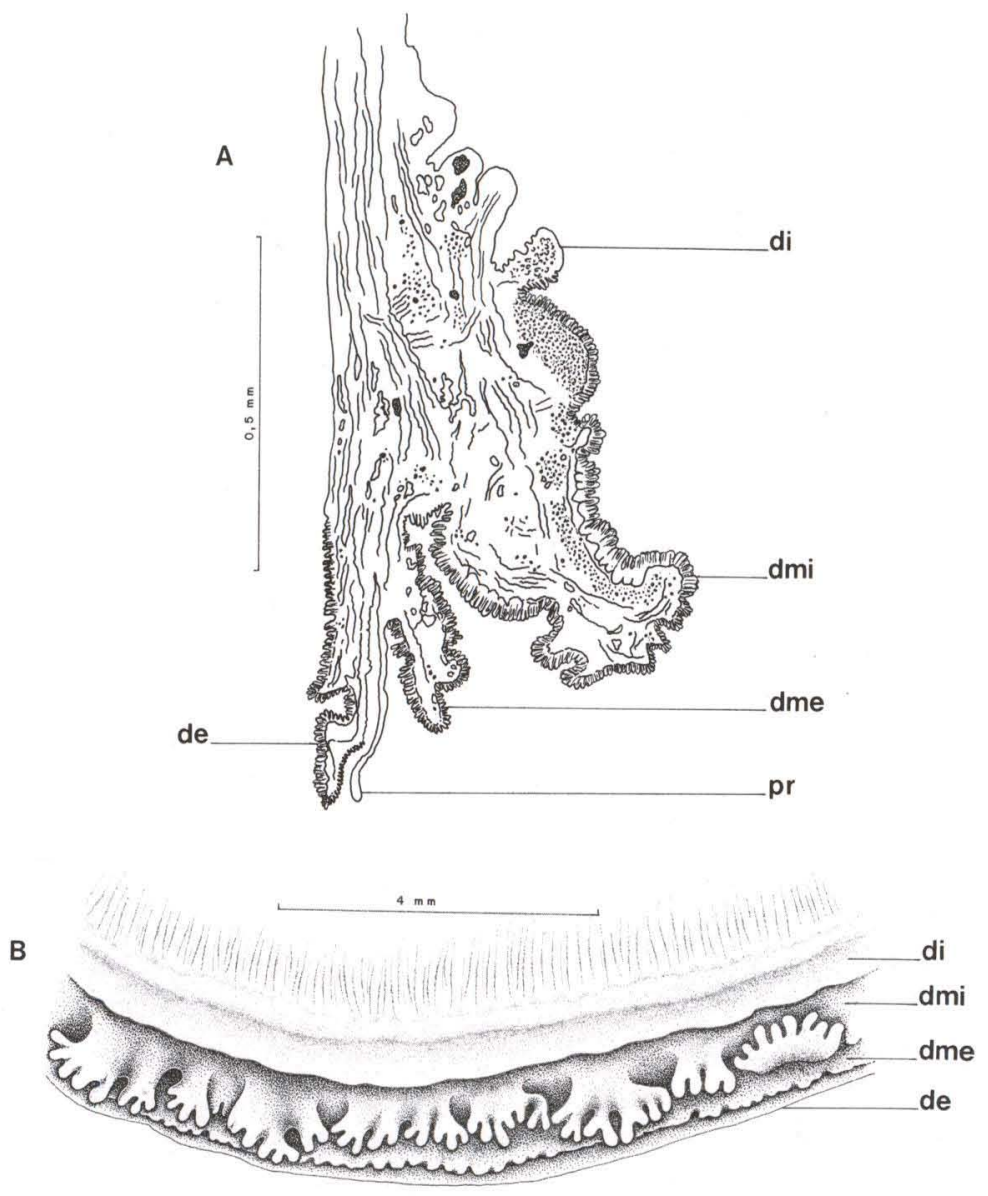

Fig. 8. Protothaca pectorina. Detalhe da borda do manto. (A) Corte transversal da borda do manto, evidenciando as quatro pregas e o local da origem do perióstraco; (B) vista parcial, na qual são visíveis as pregas com tentáculos que auxiliam na proteção da cavidade palial. (de) dobra externa, (dme) dobra mediana externa, (dmi) dobra mediana interna, (di) dobra interna ou quarta dobra, (pr) perióstraco.

\section{Músculos retratores do pé}

O pé de $P$. pectorina é achatado lateralmente, com a ponta voltada para a região anterior. Relativamente bem desenvolvido, pode ultrapassar o comprimento da concha durante a escavação.

Os músculos retratores anteriores do pé, são constituídos por dois feixes de fibras que se apoiam na face posterior do músculo adutor anterior antes de entrarem 


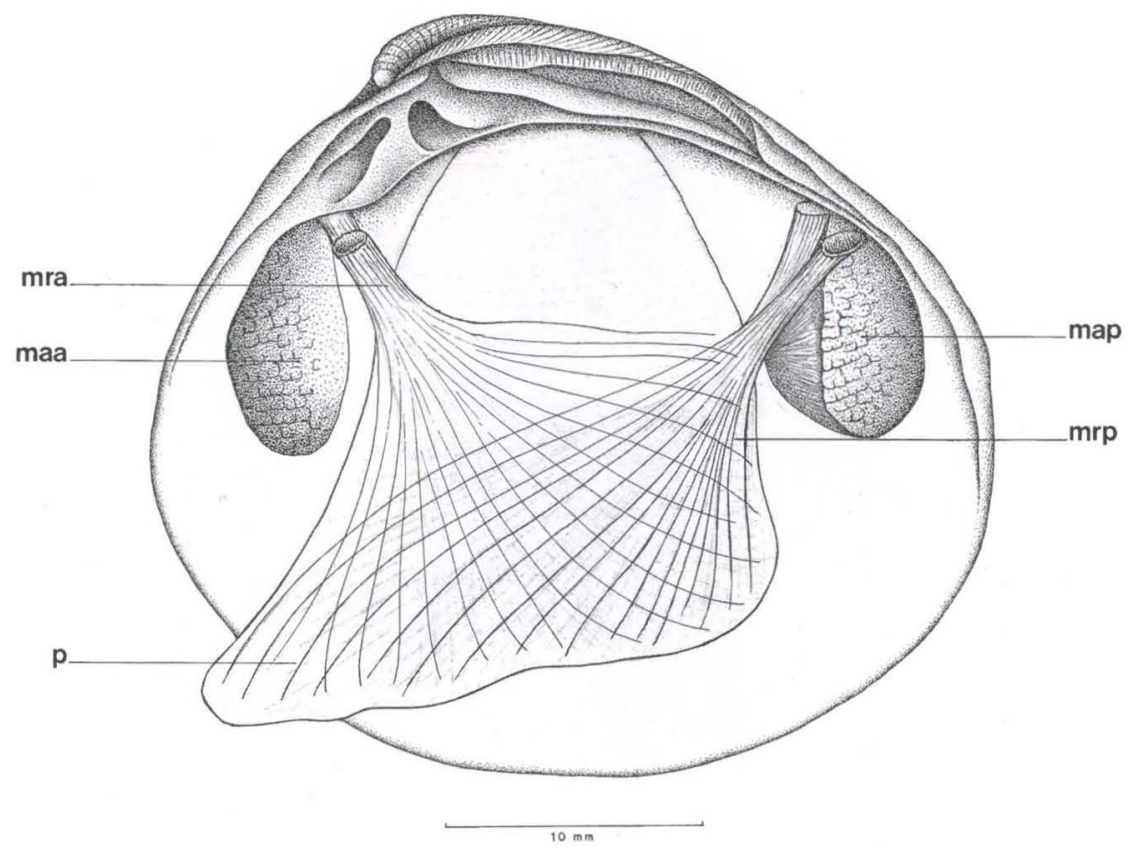

Fig. 9. Protothaca pectorina. Vista lateral da musculatura, após a remoção da valva esquerda, lobo do manto, ctenídio, palpos e massa visceral. (mas) Músculo adutor anterior, (map) músculo adutor posterior, (mra) músculo retrator anterior do pé, (mrp) músculo retrator posterior do pé, (p) pé.

no pé. O feixe de cada lado conflui para a região mediana e suas fibras ao entrarem no pé, se cruzam e se irradiam para a região ventral. Elas formam a camada mais interna do pé desde a região posterior até a anterior, com uma concentração maior de fibras na região mediana posterior. Os músculos retratores posteriores do pé se encontram também inseridos na concha acima do músculo adutor posterior e anteriormente a este. São constituídos por dois feixes que se cruzam sob o rim e se irradiam ventralmente; suas fibras dorsais se dirigem para a região anterior e ventral do pé, mas a maior parte delas se distribui na região posterior.

Protothaca pectorina não tem músculos protatores e elevadores do pé, como em outros Veneridae já estudados.

Na região da massa visceral e na proximal do pé, sob o epitélio, observaramse feixes de músculos circulares, no sentido antero-posterior. Estes envolvem a massa visceral e o pé. Fibras transversais ocorrem na parte distal do pé e na massa visceral. Podem ir de epitélio a epitélio através da massa visceral ou do epitélio esquerdo ou direito até o canal alimentar. Esses músculos intrínsecos encontram-se anteriormente ao saco do estilete e nas regiões posterior e anterior da alça ascendente do intestino médio. 


\section{Músculos das paredes do sifão}

Em $P$. pectorina os músculos da parede do sifão compõe-se de fibras longitudinais, circulares e radiais que se situam entre as camadas epiteliais externa e interna nos sifões. Logo abaixo do epitélio externo, e acima do interno, ocorre uma camada de musculatura circular pouco espessa com tecido conectivo e fibras colágenas. Entre as camadas externa e interna dos músculos circulares, observaramse duas camadas espessas de pacotes de músculos longitudinais, separadas por uma fina camada de fibras radiais.

\section{Cavidade do Manto}

\section{Topografia}

A disposição dos órgãos observados na cavidade do manto de $P$. pectorina (Fig. 10) é semelhante a de outras espécies de Veneridae já estudados. Pode-se observar que $P$. pectorina apresenta palpos labiais relativamente grandes; os ctenídios se estendem na direção posterior até a base do processo sifonal, sendo que a demibrânquia interna é maior que a externa e esta apresenta uma região supra-axial; as membranas sifonais e válvulas estão presentes na região proximal dos sifões; a abertura do pé é bem desenvolvida e a fusão das bordas do manto na linha mediana ventral ocorre na região posterior.

Foram encontrados freqüentemente em $P$. pectorina animais com brânquias partidas já em processo de regeneração, como se tivessem sido atingidas por estruturas duras que tenham penetrado na cavidade do manto. Algumas destas demibrânquias, principalmente as externas, mostravam-se tão danificadas, que pareciam trilobadas.

\section{Ctenídios}

A forma do ctenídio e o estudo das correntes presentes podem ser evidenciadas na figura $11 \mathrm{~A}$. Protothaca pectorina tem a demibrânquia interna bem desenvolvida e a externa, que é menor, apresenta a extensão supra-axial que varia em tamanho.

A secção transversal dos ctenídios de $P$. pectorina têm forma da letra "W". As demibrânquias desta espécie apresentam pigmentação nas extremidades livres, mais intensa na margem da demibrânquia interna.

A demibrânquia interna, que é mais desenvolvida que a externa, tem a metade posterior ligeiramente pregueada, enquanto que a demibrânquia externa apresenta essa mesma região ondulada. As metades anteriores das demibrânquias são lisas.

Em P. pectorina (Fig. 12 A,B), a sucessão de cortes histológicos das duas demibrânquias não evidenciaram filamentos que poderiam ser chamados de principais; neste caso os ctenídios dessa espécie classificam-se como homorábdicos, diferentes da maioria dos Veneridae. As partes pregueadas das demibrânquias de $P$. pectorina apresentam, em média, quatorze filamentos por prega para a demibrânquia externa e dezessete para a interna.

Os ctenídios de $P$. pectorina nertencem ao tipo C (1a) (ATKINS 1937). Existem duas correntes visíveis de direção oral, uma ao longo do eixo do ctenídio, entre as demibrânquias externa e interna e outra no sulco ventral da demibrânquia interna (Fig. 11A). 


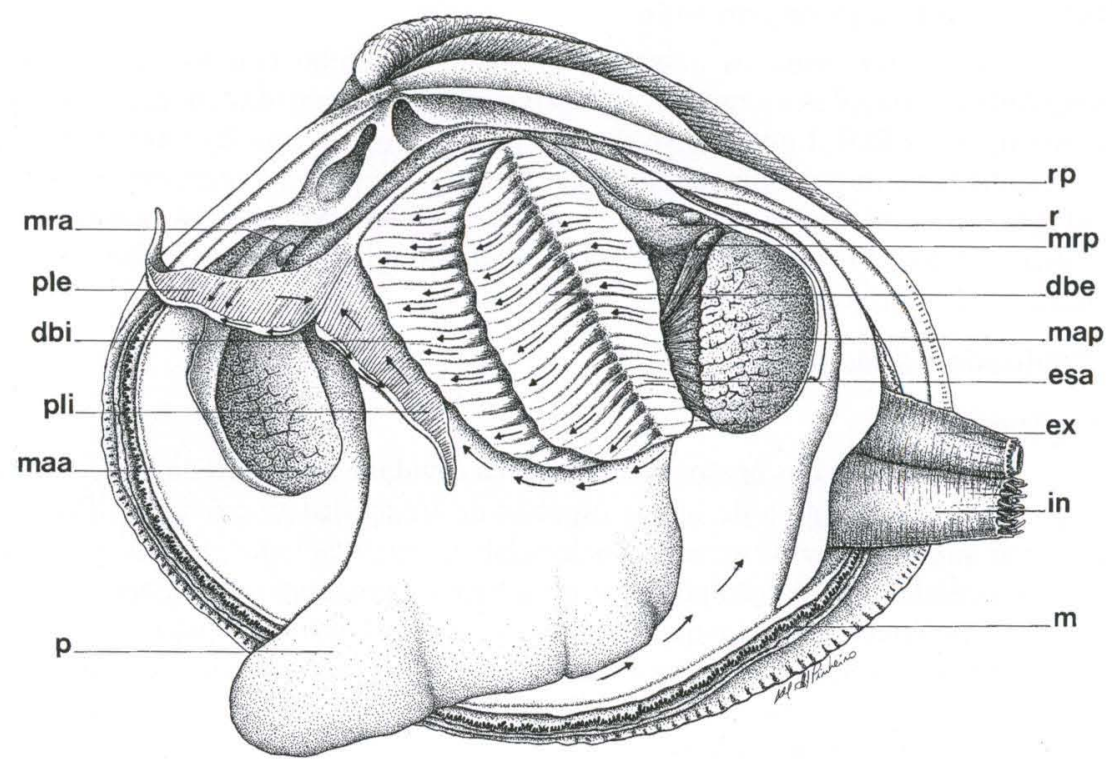

$10 \mathrm{~mm}$

Fig. 10. Protothaca pectorina. Topografia da cavidade do manto após a remoção da valva esquerda e do lobo esquerdo do manto. (dbe) Demibrânquia externa, (dbi) demibrânquia interna, (essa) extensão supra-axial, (ex) sifão exalante, (m) manto, (maa) músculo adutor anterior, (map) músculo adutor posterior, (mra) músculo retrator anterior do pé, (mrp) músculo retrator posterior do pé, (p) pé, (ple) palpo labial externo, (pli) palpo labial interno, (r) rim, (rp) região do pericárdio.

Foram observadas correntes frontais de direção ventral na lamela ascendente da demibrânquia externa. Na porção distal da lamela descendente da mesma demibrânquia as correntes têm direção ventral e na porção mediana proximal, têm direção dorsal. Em $P$. pectorina constatou-se a ausência de uma corrente oral na margem livre da demibrânquia externa.

As partículas maiores conduzidas pelas correntes frontais das lamelas ascendentes das demibrânquias externas, quando chegam às extremidades das mesmas, passam para as correntes frontais das lamelas homólogas das demibrânquias internas, e quando chegam à margem são aproveitadas pela corrente oral longitudinal da extremidade livre ou são expelidas para a cavidade do manto.

Na demibrânquia interna, as correntes das lamelas descendentes e ascendentes são conduzidas ventralmente. Existe um conjunto de cílios na região dorsal ou proximal das lamelas descendentes das demibrânquias, que vibram em direção ao eixo dos ctenídios, onde as partículas são conduzidas pela corrente axial para a região oral. Na margem ventral desta demibrânquia observou-se um sulco marginal, cuja corrente longitudinal carrega partículas também em direção oral. 


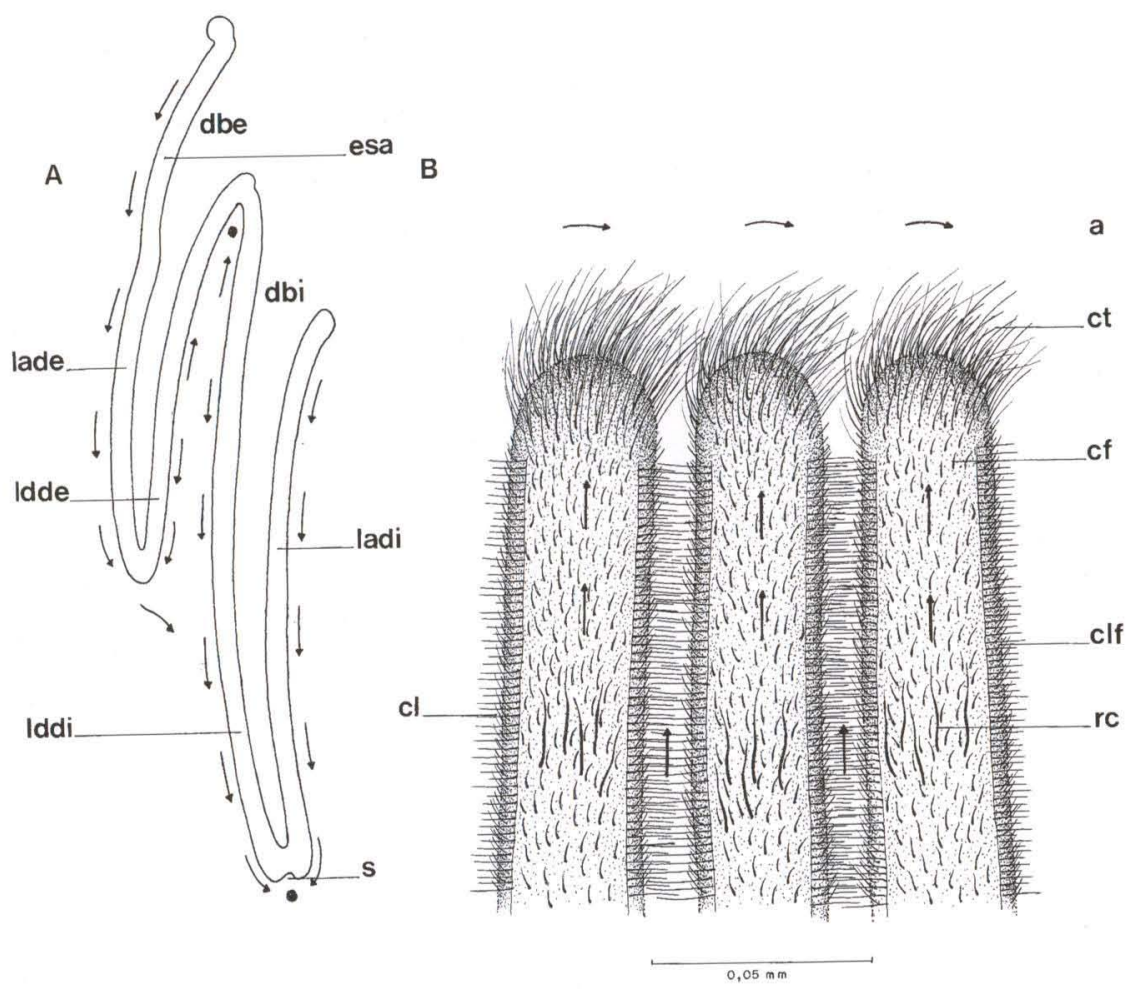

Fig. 11. Protothaca pectorina. (A) Esquema da secção transversal do ctenídio: (dbe) demibrânquia externa, (dbi) demibrânquia interna, (essa) extensão supra-axial da demibrânquia externa, (lade) lamela ascendente da demibrânquia externa, (ladi) lamela ascendente da demibrânquia interna, (Idde) lamela descendente da demibrânquia externa, (Iddi) lamela descendente da demibrânquia interna, (s) sulco marginal, correntes com direção oral; (B) porção da superfície externa da lamela interna mostrando a ciliação, (cf) cílios frontais, (cl) cílios laterais, (clf) cílios latero-frontais, (ct) cilios terminais, (re) cílios limpadores. As setas indicam a direção das correntes ciliares, inclusive a que é dirigida para a região anterior (a).

Os filamentos e os cílios dos ctenídios de $P$. pectorina são semelhantes aos de outros Veneridae já estudados.

Os cílios látero-frontais (clf) (Figs 11B, 12) possuem $9 \mu \mathrm{m}$ de comprimento, e se localizam entre os filamentos; são relativamente rígidos, projetam-se perpendicularmente para fora dos filamentos e se entrecruzam, formando um trato cuja função lembra a de uma peneira, impedindo que certas partículas penetrem no espaço entre os filamentos.

Os cílios frontais (cf) atingem a $5 \mu \mathrm{m}$ de comprimento, vibram intensamente em toda a superfície livre dos filamentos. Do mesmo modo, os cílios laterais (cl) vibram constantemente entre os cílios látero-frontais, promovendo forte corrente. Estes cílios em $P$. pectorina têm um comprimento de $7 \mu \mathrm{m}$. 
A

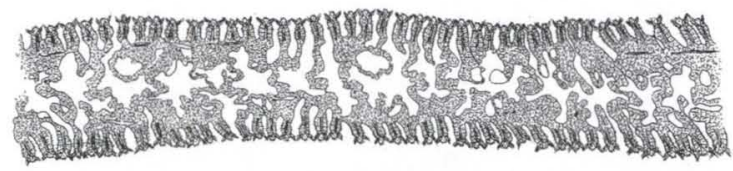

$0,8 \mathrm{~mm}$

B
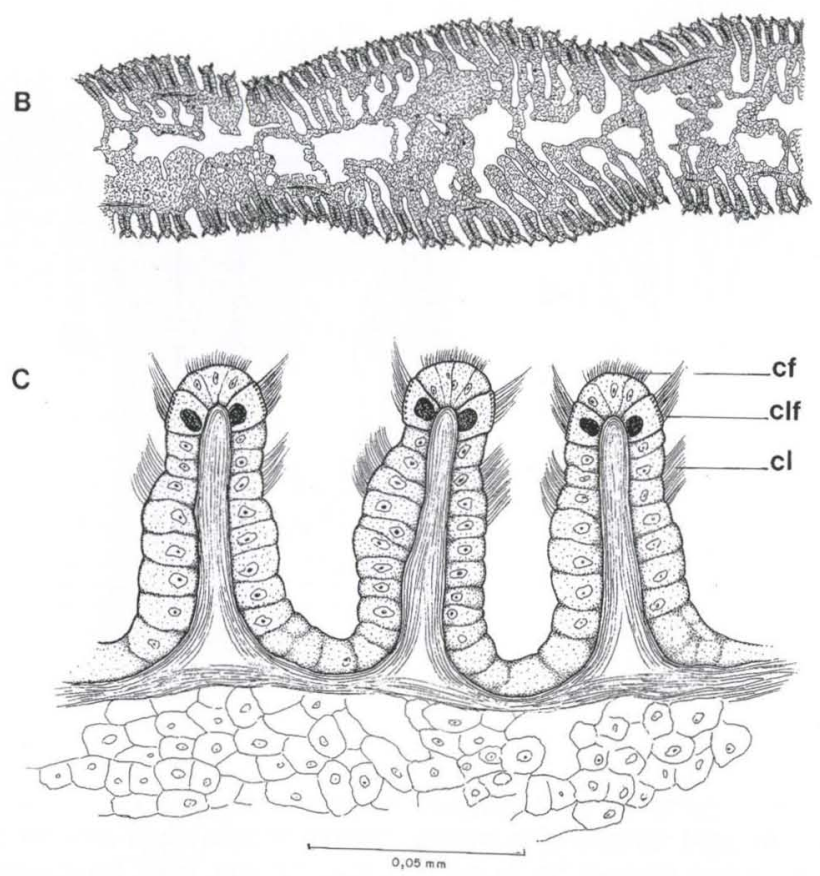

Fig. 12. Protothaca pectorina. (A) Secção transversal da porção mais anterior da demibrânquia interna, sem pregas; (B) secção transversal da porção mais posterior da demibrânquia interna, levemente pregueada; (C) seção horizontal da demibrânquia interna evidenciando a disposição dos filamentos da demibrânquia externa para a evidenciação da disposição dos cílios, (cf) cílios frontais, (cl) cílios laterais, (clf) cílios latero-frontais. Ctenídios homorábdicos.

Nas extremidades das demibrânquias interna e externa observou-se a presença de cílios terminais com um comprimento de $22 \mu \mathrm{m}$, cuja vibração produz uma corrente oral.

Em $P$. pectorina verificou-se na demibrânquia externa a presença de cílios limpadores (rc), que vibram como chicotes, removendo material não aproveitável.

\section{Palpos labiais}

Os palpos labiais de P. pectorina (Fig. 13) são triangulares, achatados, grandes, medindo cerca de $1,2 \mathrm{~cm}$ de extensão em um animal de quatro centímetros de comprimento. Apresentam pigmentação sépia que se torna mais intensa nas extremidades livres e em volta da boca. 


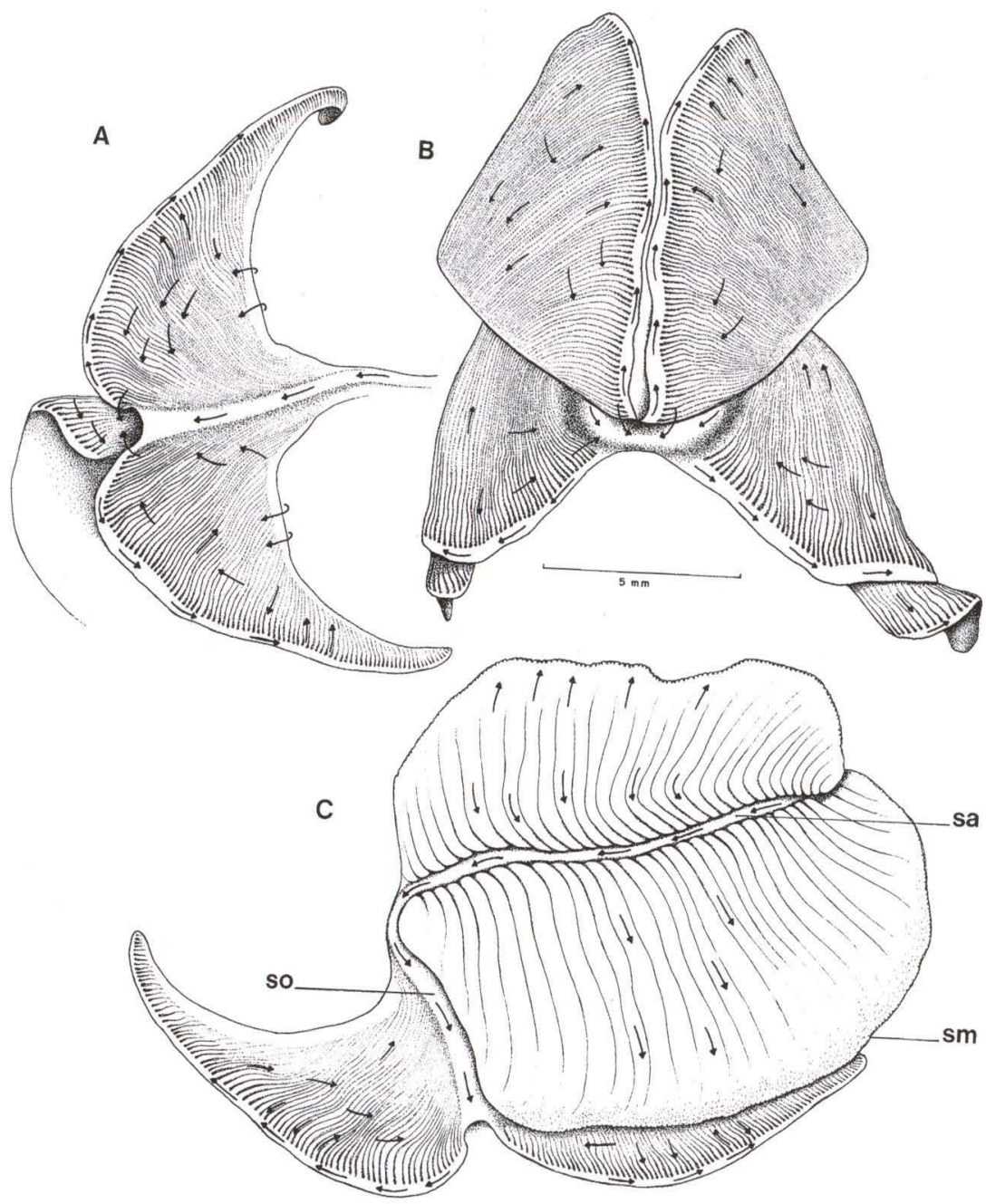

Fig. 13. Protothaca pectorina. (A) Vista lateral dos palpos labiais esquerdos evidenciando as correntes ciliares na região interna; $(B)$ vista frontal da região bucal mostrando as faces internas dos palpos labiais e o característico enrolamento dos mesmos; (C) associação dos palpos labiais e da demibrânquia do lado esquerdo do animal; as setas indicam as correntes ciliares. (sa) Sulco axial, (so) sulco oral, (sm) sulco marginal.

Protothaca pectorina apresenta na região proximal dos palpos internos e externos uma área lisa onde os sulcos oral, proximal e distal, estão intimamente ligados à parte proximal da demibrânquia interna, e pertencem à Categoria II da associação dos palpos e ctenídios (STASEK 1963). As superfícies internas dos palpos são pregueadas (Fig. 13 A,B,C) e a externas lisas. Possuem grande atividade muscular e a atividade ciliar é muito eficiente na separação de partículas. Protothaca 
pectorina apresenta nas faces internas numerosas pregas finas cujo número varia de oitenta a oitenta e dois. Essas pregas são delimitadas dorsalmente e ventralmente por uma região lisa com atividade ciliar própria.

Os palpos externos estão localizados entre o manto e a lamela descendente da demibrânquia interna, e os palpos internos entre a lamela ascendente da mesma demibrânquia e a massa visceral.

O material captado pelos ctenídios é encaminhado para os palpos através das demibrânquias interna e externa, sulco marginal, sulco axial e sulco oral distal. As partículas provenientes das lamelas da demibrânquia interna e do sulco oral distal atingem a superfície pregueada dos palpos quase diretamente. As partículas localizadas superficialmente à massa visceral são captadas pela superfície lisa da face externa dos palpos internos e em seguida conduzidas para a superfície pregueada dos mesmos. A superfície lisa dos palpos externos pode captar as partículas em suspensão existentes no líquido circundante da cavidade palial.

Em $P$. pectorina foram observadas as seguintes correntes indicadas nos esquemas diagramáticos do corte transversal às pregas dos palpos (Fig. 14A,B): a de aceitação "a" ocorrendo dorsalmente às pregas e encaminhando de ápice a ápice, em direção à boca, partículas até o sulco oral proximal; na porção basal entre as pregas adjacentes há uma corrente de rejeição "c" a qual envia partículas em direção à margem ventral lisa do palpo, que as encaminham a região posterior e ao ápice do palpo de onde são transferidas para o manto; uma corrente de rejeição "b", encontrada na superfície superior das pregas, dirige as partículas ventralmente ao encontro da corrente de rejeição da margem livre; na região mediana, no lado proximal entre as pregas há uma corrente de reaceitação "d", que conduz o material para a margem dorsal; cílios desenvolvidos localizados no ápice da prega desta região mediana de corrente mais forte são encarregados de captar as partículas para reaceitação; estas serão capturadas pela corrente de aceitação "a" e levadas em direção oral. Na região distal entre as dobras mais abaixo da corrente anterior, há também uma corrente mais fraca de reaceitação "e".

Quando pouca quantidade de material chega aos palpos labiais, verifica-se uma movimentação das pregas sobrepondo-se às adjacentes, de maneira a facilitar que o material seja carregado em direção ao sulco oral e boca pelas correntes de aceitação da parte superior das pregas. Caso quantidades excessivamente grandes de material sejam conduzidas à mesma, os palpos reagem bruscamente tomando a forma de uma espiral devido a contrações sucessivas, forçando a rejeição da maior parte das partículas. Finalmente, quando a quantidade de material é de proporção razoável, as pregas parecem permanecer eretas dando espaço para que uma boa parte desse material seja rejeitado pelas correntes de rejeição dos sulcos e consequentemente das margens lisas ventrais. Parece também que as correntes de reaceitação dorsais se intensificam e, neste caso, reconduzem o material para as correntes de aceitação de superfície interna dos palpos.

\section{Correntes ciliares da superfície da massa visceral}

As correntes ciliares foram observadas na superfície da massa visceral após a retirada do manto e do ctenídio (Fig. 15). Ocorrem desde a junção da lamela ascendente da demibrânquia interna até a região que faz limite com o pé e funcionam

Revta bras. Zool. 17 (4): 1007 - 1039, 2000 
A
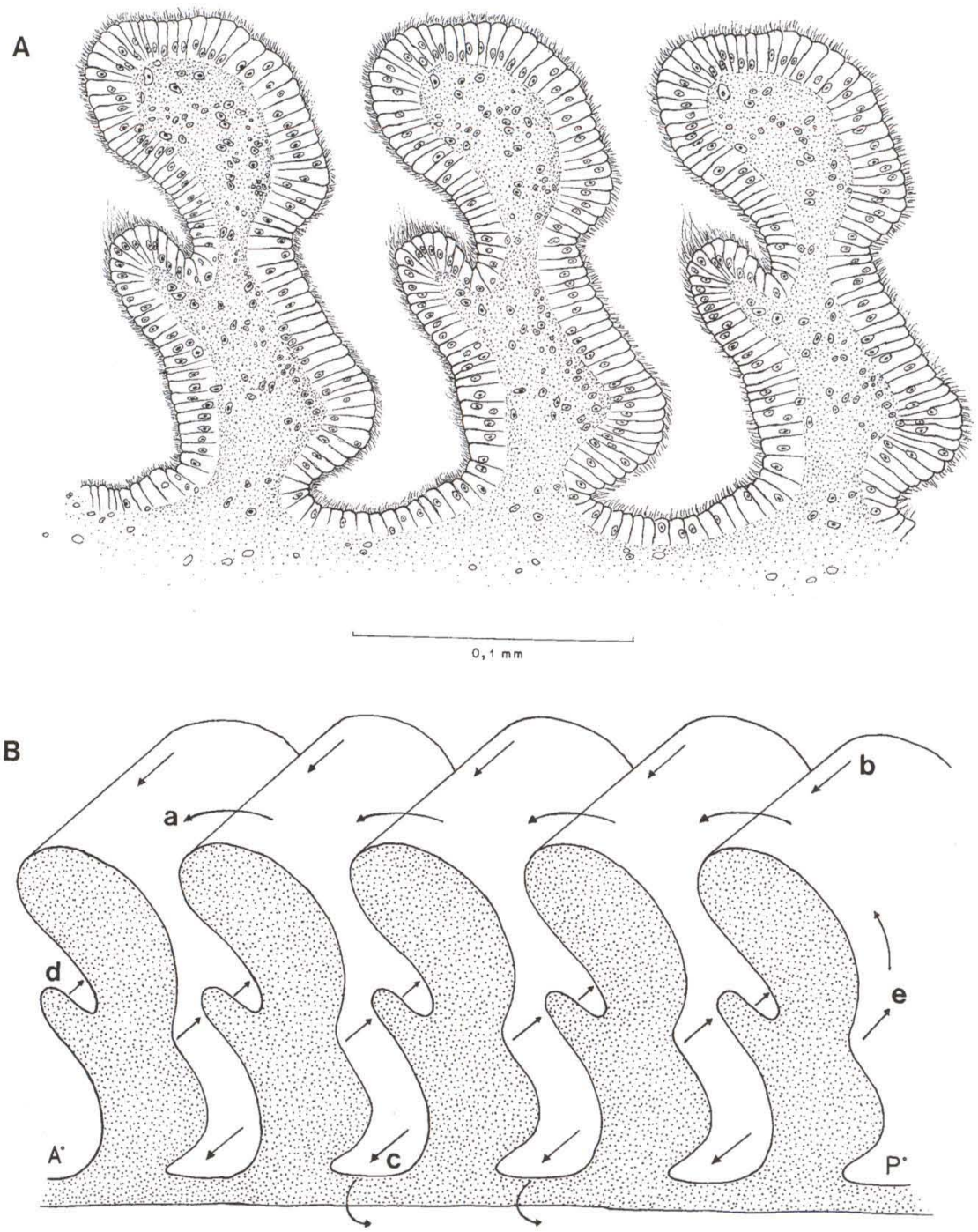

Fig. 14. Protothaca pectorina. (A) Corte histológico das pregas dos palpos labiais; (E) esquema da estrutura das pregas dos palpos labiais e das correntes ciliares que nelas ocorrem; $(A)$ região anterior; $(\mathrm{P})$ região posterior, (a) corrente de aceitação transversal, (b) corrente de rejeição da extremidade livre da prega, (c) corrente de rejeição no assoalho do sulco entre as pregas, (d) corrente de reaceitação na metade da face anterior da prega, (e) corrente de reaceitação na metade da face posterior das pregas.

no reaproveitamento do material que chega a superfície da massa visceral. São mais intensas na região anterior e mais fracas na posterior.

As correntes mais fortes encaminham partículas ventralmente em direção à margem livre da demibrânquia interna e do palpo labial interno, onde podem ser 


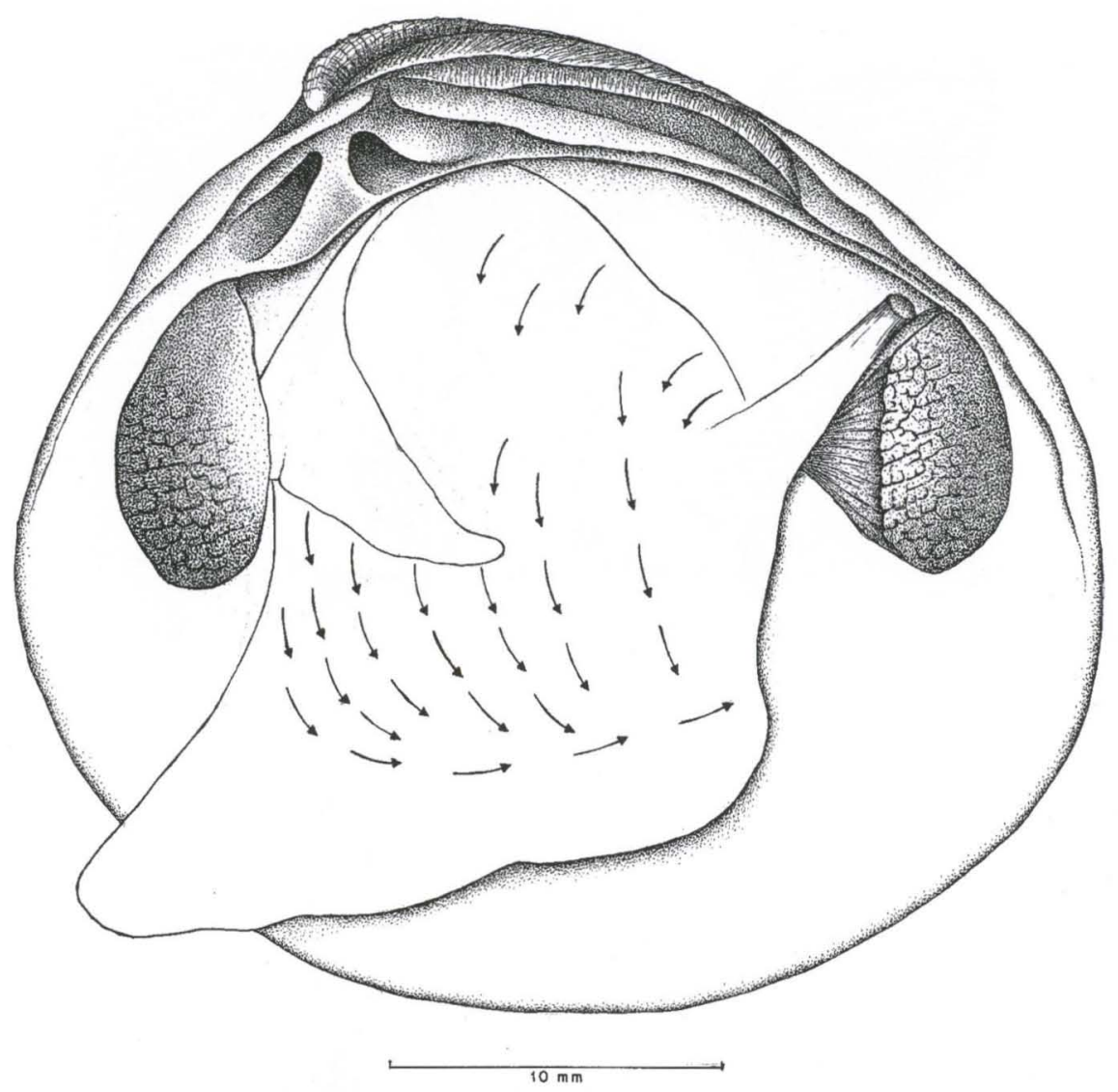

Fig. 15. Protothaca pectorina. Correntes ciliares sobre a superficie da massa visceral após a retirada dos ctenídios e palpos labiais.

reaproveitadas por ambos os órgãos. Os cílios da face lisa dos palpos labiais captam as partículas, conduzem-nas para a sua margem dorsal e, em seguida, para a face pregueada onde são selecionadas.

$\mathrm{Na}$ área onde a atividade ciliar é mais fraca, ou seja, na região posterior, as partículas são enviadas em direção à corrente de rejeição que limita o pé e algumas são encaminhadas para a região anterior antes de se juntarem a esta corrente, podendo ser reaproveitadas pela demibrânquia interna e palpo labial interno. Quando o material não é aproveitado por estas estruturas, é conduzido lateralmente sobre a massa visceral pelo poderoso trato de rejeição próximo ao pé, que carrega as partículas para a região posterior, onde se acumulam na base do sifão inalante.

\section{Correntes ciliares da superfície do manto}

Em $P$. pectorina, as correntes de rejeição de partículas da superfície do manto (Fig. 16) as conduzem anteriormente em direção aos palpos, e depois ventralmente, onde elas são reunidas por uma forte corrente de rejeição. Esta é paralela à margem do manto e acumula as partículas da base do sifão inalante por onde são eliminadas. 
Para evidenciar os mecanismos ciliares na superfície do manto, ctenídios e palpos, apresenta-se na figura 17 uma visão esquemática conforme foi feito para os Semelidae por DOMANESCHI (1995).

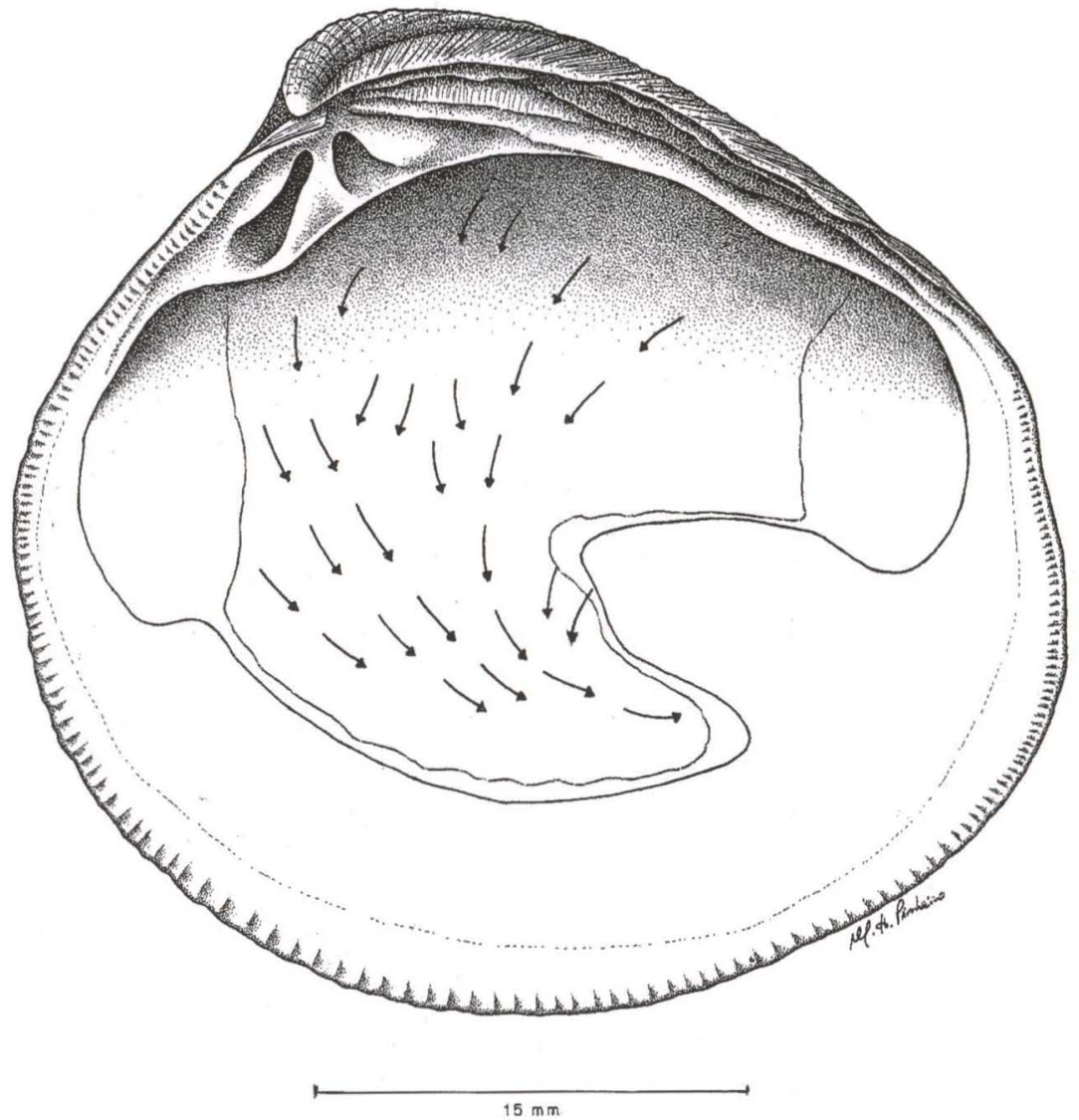

Fig. 16. Protothaca pectorina. Correntes ciliares sobre a superfície do manto. A massa visceral e os ctenídios foram removidos e o lobo direito do manto foi exposto.

\section{Canal alimentar}

\section{Estrutura geral}

A estrutura geral do canal alimentar de $P$. pectorina (Fig. 18) é muito semelhante a dos Veneridae já estudados.

A boca, de formato oval, se situa na extremidade antero-dorsal apresentando pigmentação marrom. É circundada pelos palpos labiais que apresentam o mesmo tipo de pigmento no sulco oral proximal. Continua-se com o esôfago relativamente longo, achatado dorso-ventralmente, o qual é revestido por rugas epiteliais finas, longitudinais e intensa pigmentação melânica. Este termina na região antero-ventral do estômago globular, que está recoberto pelo divertículo digestivo na região lateral 


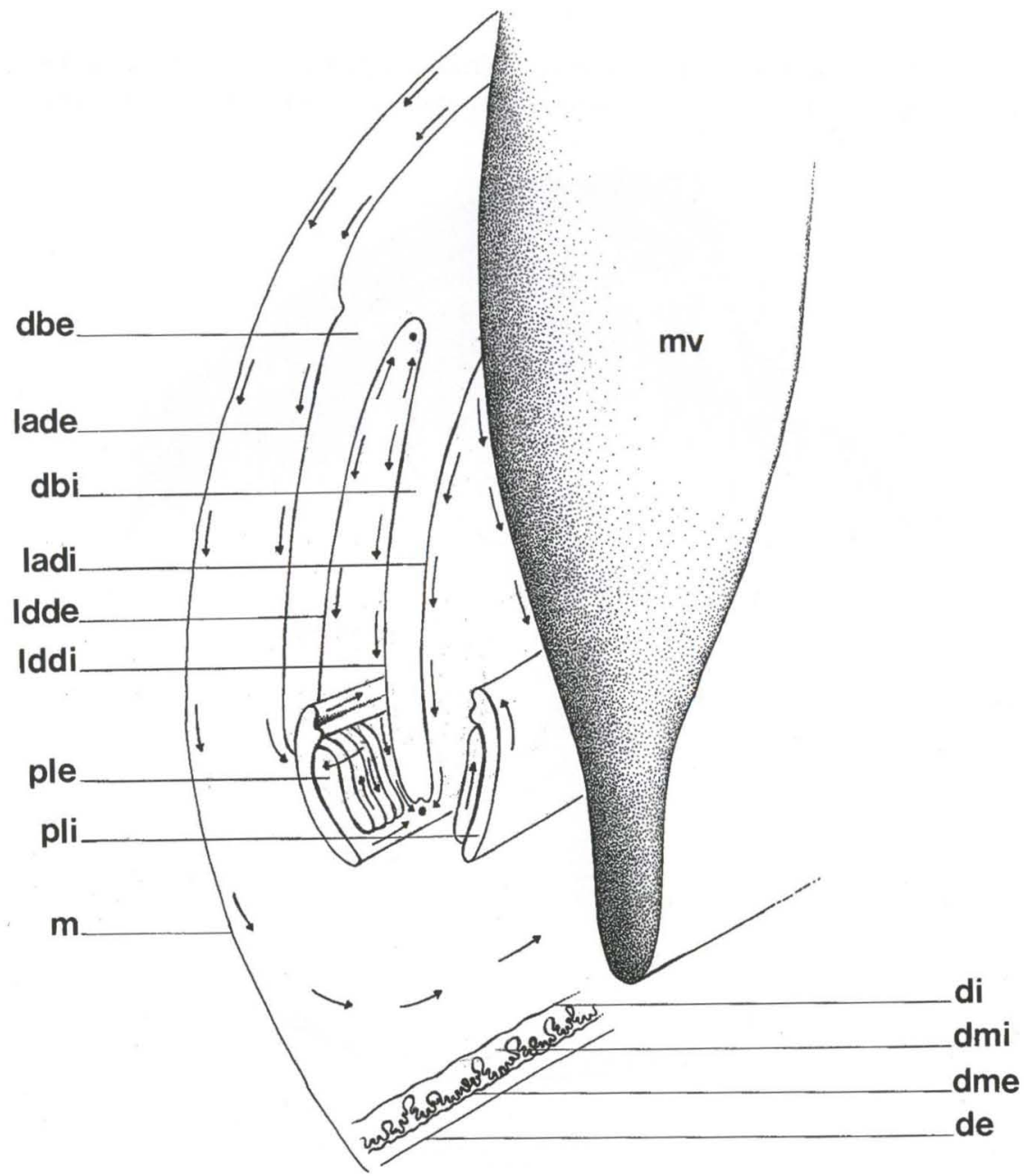

Fig. 17. Protothaca pectorina. Representação esquemática dos mecanismos ciliares da metade direita da cavidade palial. (dbe) Demibrânquia externa, (dbi) demibrânquia interna, (de) dobra externa da borda do manto, (dme) dobra mediana externa da borda do manto, (dmi) dobra mediana interna da borda do manto, (di) dobra interna da borda do manto, (lade) lamela ascendente da demibrânquia externa, (ladi) lamela ascendente da demibrânquia interna, (Idde) lamela descendente da demibrânquia externa, (Iddi) lamela descendente da demibrânquia interna, $(\mathrm{m})$ lobo do manto, (mv) massa visceral, (ple) palpo labial externo, (pli) palpo labial interno, $(\bullet)$ corrente de aceitação.

anterior. O intestino, que se inicia na região postero-ventral do estômago, está unido ao saco do estilete e ambos são incompletamente separados pelas tiflossoles maior e menor. O intestino médio se inicia na porção distal deste tubo, e dá quatro voltas seguidas na região anterior e ventral do estômago. Após isso forma o intestino posterior, que se encaminha dorsalmente próximo à região posterior do saco do

Revta bras. Zool. 17 (4): 1007 - 1039, 2000 
estilete. O intestino posterior atravessa o pericárdio, penetra no ventrículo e bulbo aórtico. Continua-se posteriormente, descreve um arco sobre o músculo adutor posterior e termina na papila anal.

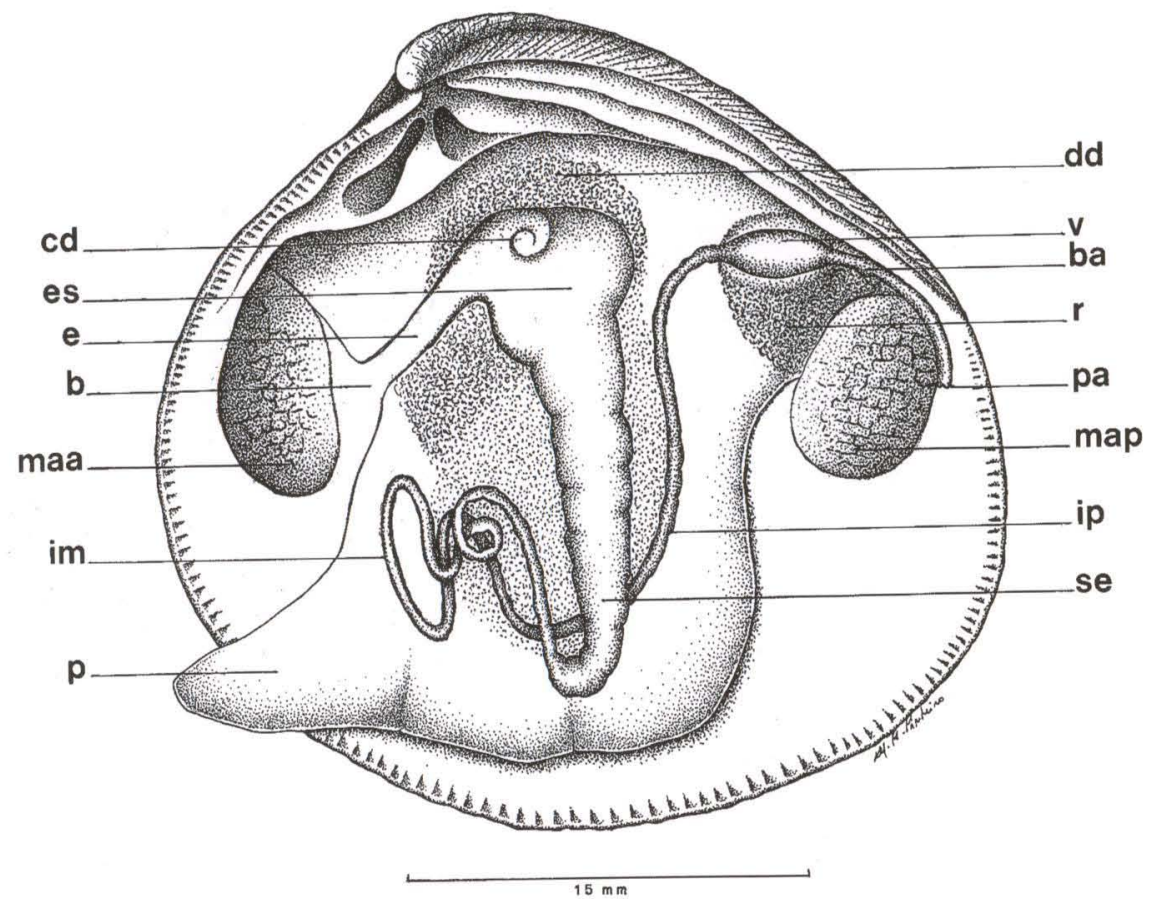

Fig. 18. Protothaca pectorina. Aparelho digestivo visto do lado esquerdo. (b) Boca, (ba) bulbo aórtico, (cd) capuz dorsal, (dd) divertículo digestivo, (e) esôfago, (es) estômago, (im) intestino médio, (ip) intestino posterior, (maa) músculo adutor anterior, (map) músculo adutor posterior, (p) pé, (pa) papila anal, (r) rim, (se) saco do estilete, (v) ventrículo.

\section{Estrutura detalhada do estômago}

O estômago de $P$. pectorina pertence ao tipo V (PURCHON 1960; 1987), e sua estrutura detalhada é representada na figura 19.

O esôfago (e) termina na região antero-ventral do estômago globular e o orifício do esôfago é delimitado por um sulco anterior (sc), denominado de trato circular por ANSELL (1961), que se continua no teto do estômago. Logo abaixo do sulco circular existe uma área de seleção estreita (sa7) que apresenta pigmentação marrom.

O saco do estilete (se) e o intestino médio (im) são intimamente unidos, e dirigem-se para a região inferior, dentro da massa visceral

O capuz dorsal (cd) em P. pectorina é bem desenvolvido, possui uma pigmentação alaranjada o que facilita sua identificaçãn e se curva para o lado esquerdo do teto do estômago. 


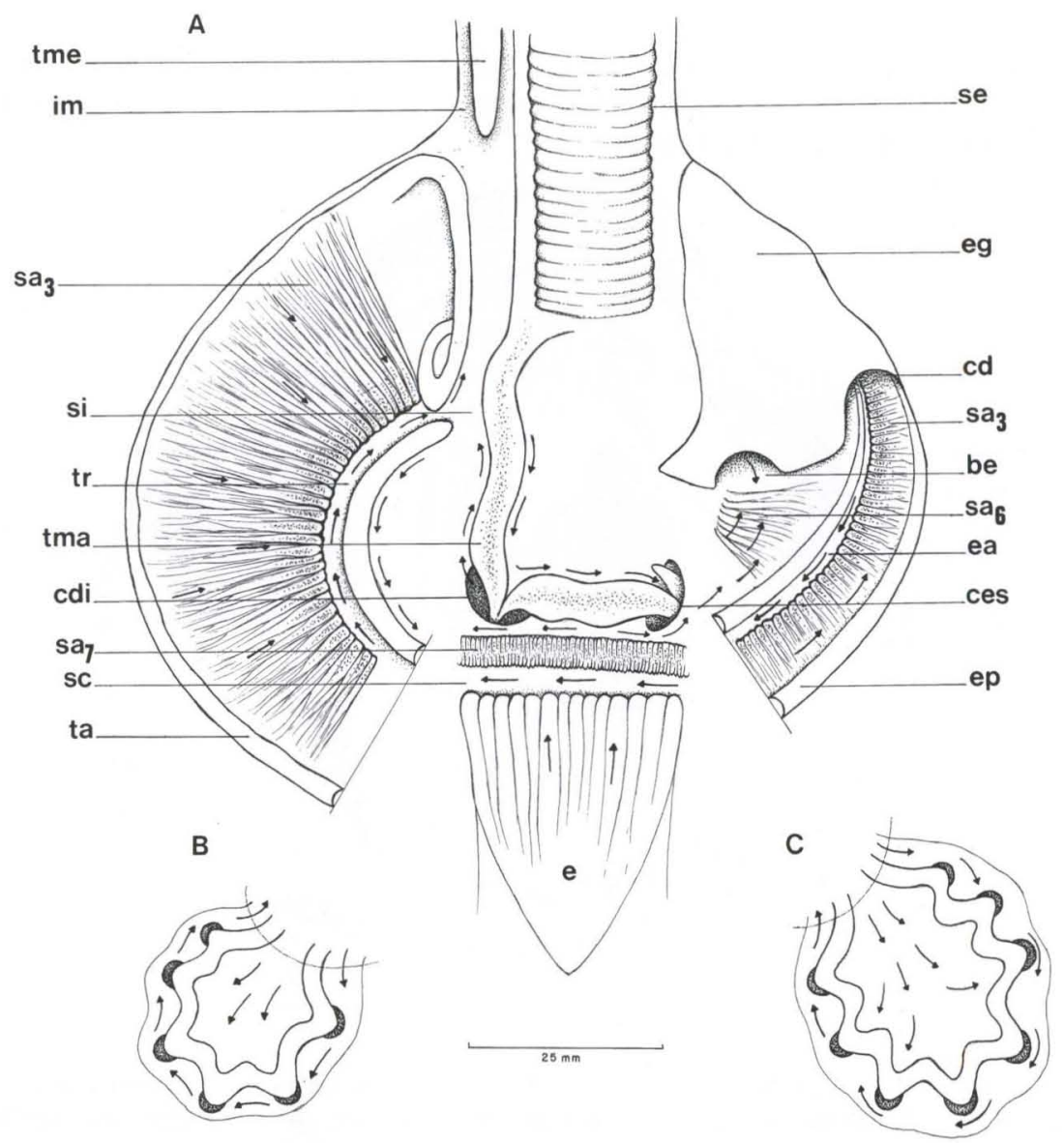

Fig. 19. Protothaca pectorina. Estrutura e correntes ciliares principais do estômago e cecos direito e esquerdo. (A) Estômago aberto dorsalmente, (B) ceco direito, (C) ceco esquerdo. As setas indicam a direção das correntes ciliares principais, (be) bolsa esquerda, (cd) capuz dorsal, (cdi) ceco direito, (ces) ceco esquerdo, (e) esôfago, (ea) elevação anterior, (eg) escudo gástrico, (ep) elevação posterior, (im) intestino médio, (sa3) área de seleção principal do capuz dorsal, (sa6) área de seleção da bolsa esquerda, (sa7) área de seleçăo abaixo do orifício do esôfago, (sc) sulco circular, (se) saco do estilete, (si) sulco intestinal, (tma) tiflossole maior, (tme) tiflossole menor, (ta) trato de aceitação, (tr) trato de rejeição.

A tiflossole menor (tme) termina no lado direito do estômago, próximo ao orifício do intestino médio. A tiflossole maior (tma), pigmentada dorsalmente, permanece na parede direita sendo acompanhada pelo sulco intestinal (si). Ela se continua através do assoalho do estômago e entra no ceco direito (cdi). Ao emergir deste, atravessa o assoalho do estômago logo abaixo da área de seleção sa7, penetra no ceco esquerdo (ces) e termina na abertura do mesmo no assoalho do estômago. 
O ceco direito tem a parte inferior voltada para baixo, um pouco afastado da linha mediana e recebe a dobra da tiflossole maior. Ali se abrem seis dutos do divertículo digestivo sendo que duas aberturas se localizam na parede posterior, duas na parede ventral e duas na anterior. O ceco esquerdo, mais desenvolvido do que o direito, recebe oito dutos do divertículo digestivo.

Um finíssimo escudo gástrico (eg) recobre o teto e grande parte da parede esquerda do estômago, emitindo duas projeções que entram respectivamente nas aberturas da bolsa esquerda (be) e do capuz dorsal.

A bolsa esquerda (be) se abre na parede esquerda do estômago acima da abertura do ceco esquerdo (ces) e apresenta uma área de triagem muito pouco desenvolvida ( $\mathrm{sa}_{6}$ ) na proximidade de sua abertura.

Na parede anterior do teto do estômago, ocupando também parte da parede direita, encontra-se uma grande área de seleção (sa3) que tem pregas com pigmentação marrom. Esta área de triagem converge partículas para o trato de rejeição (tr) e daí para o sulco intestinal. Esse trato de rejeição se inicia no capuz dorsal e é delimitado pela elevação anterior (ea). Um trato de aceitação (ta) pode ser observado no limite distal da área de triagem sa3.

Nos cecos direto e esquerdo, correntes ciliares dirigem as partículas não aproveitadas das aberturas dos dutos do divertículo digestivo para o sulco intestinal e daí para a abertura do intestino médio.

\section{DISCUSSÃO}

A consideração dos Veneridae encontrados na Praia do Cardo, Sepetiba, Estado do Rio de Janeiro, possibilita analisar os mais importantes fatos anatômicos relacionados ao modo de vida de $P$. pectorina, e compará-los aos de outras espécies que ocorrem no mesmo local, e têm o mesmo hábito de cavar.

Durante as coletas de $P$. pectorina, assim como no aquário em laboratório, foram realizadas várias observações sobre o mecanismo de escavação e a velocidade com que se enterram no substrato. O tempo para se enterrar completamente variou muito: em laboratório foi de quatro a sessenta minutos, mas no ambiente natural, alguns animais levaram menos tempo. Espécimes menores de $P$. pectorina enterram-se mais rapidamente. Segundo STANLEY (1970) a velocidade de penetração está relacionada com a forma e com a ausência de estruturas co-marginais fortes que retardam a escavação.

Protothaca pectorina cava superficialmente e possui mobilidade horizontal. A direção do movimento durante a penetração no sedimento foi também relacionada com a forma da concha (STANLEY 1970). Para muitas das espécies de bivalves que usam o movimento da "cadeira de balanço", a penetração no substrato não é vertical mas tem um componente que dirige a concha para a frente. Este componente existe nos Veneridae em geral e está presente na espécie aqui tratada, como também em A. brasiliana (NARCHI 1972) e em C. subrostrata (NARCHI \& GABRIELI 1980).

Ao contrário de $P$. pectorina, C. subrostrata e A. brasiliana apresentam linhas concêntricas pouco mais acentuadas. De acordo com STANLEY (1970), estas três espécies são cavadoras mais rápidas do que as que possuem esculturas muito desenvolvidas. 
O tamanho dos espécimes de $P$. pectorina estudados nesta pesquisa foram bem maiores que os de $A$. brasiliana (NARCHI 1972) e C. subrostrata (NARCHI \& GABRIELI 1980).

Os sifões de $P$. pectorina pertencem ao tipo B (YoNGE 1948, 1982), são mais desenvolvidos do que os de $A$. brasiliana (NARCHI 1972) e C. subrostrata (NARCHI \& GABRIELI 1980). São unidos praticamente em todo o seu comprimento, e têm os tentáculos dos sifões dispostos de forma muito semelhante à de $A$. brasiliana e $C$. subrostrata. $\mathrm{O}$ anel de tentáculos presente em $P$. pectorina, formado pela dobra mediana, não ocorre ao redor das aberturas em A. brasiliana e $T$. mactroides (NARCHI 1972). O fato de determinados Veneridae possuírem sifões curtos e fundidos, foi considerado como primitivo por ANSELL (1961).

O sifão inalante é uma estrutura essencial para os bivalves que se alimentam de material em suspensão, pois é através deste que a água e as partículas são drenadas para dentro da cavidade do manto. Os tentáculos dos sifões de $P$. pectorina são simples e não muito desenvolvidos, o que parece concordar com o fato de que essas espécies vivem em águas calmas, como acontece com $A$. brasiliana e C. subrostrata. Realmente estas espécies são sempre encontradas em praias areno-lodosas de enseadas e baías abrigadas, sem arrebentação de ondas, e onde a movimentação da água é pequena.

Os sifões da espécie em estudo são também muito sensíveis a estímulos mecânicos, assim como os de A. brasiliana (NARCHI 1972) e C. subrostrata (NARCHI \& GABRIELI 1980). OWEN (1953) e NARCHI (1972) consideraram esta sensibilidade uma adaptação a ambientes de águas calmas.

A presença de pequenas manchas brancas na região interna da abertura dos sifões poderia servir para camuflar a espécie em um fundo claro (JONES 1979).

Duval (1963) estudou a musculatura dos sifões de alguns Veneridae, a qual se assemelha à de $P$. pectorina. Consiste de uma camada externa de músculos circulares, uma interna igualmente de músculos circulares porém muito pouco definida e um corpo principal de músculos longitudinais entremeados por músculos circulares.

$\mathrm{Na}$ base dos sifões inalante e exalante ocorrem as membranas sifonais ou válvulas, que podem se elevar ou abaixar. KELLOGG (1915) relacionou a presença da membrana sifonal com o canal de rejeição, mas nos Veneridae (NARCHI 1972) a membrana sifonal nunca é acompanhada pelo canal de rejeição. Ao se elevar a membrana sifonal permite a entrada de água na cavidade do manto; ao se abaixar, dirige a água ventralmente para a região onde as pseudofezes se acumulam anteriormente aos sifões, ou suspende este material de rejeição para a sua eliminação da cavidade do manto, através do sifão inalante. Em P. pectorina as válvulas do sifão inalante são ligeiramente onduladas em suas extremidades livres, controlam o volume da água que entra e ajudam na expulsão das pseudofezes.

Em A. brasiliana e em T. mactroides não ocorre ao redor das duas aberturas o anel de tentáculos formado pela dobra mediana (NARCHI 1972).

Assim como os sifões, o manto tem a função de selecionar partículas. Observou-se que as espécies que vivem na zona de fluxo e refluxo das marés têm necessidade de maior proteção, pois a quantidade de partículas em suspensão é sempre maior. 
Em P. pectorina a borda do manto é formada por quatro dobras características, o que ocorre comumente nos membros da família Veneridae Rafinesque, 1815, segundo ANSELL (1961), confirmado posteriormente por outros autores (NARCHI 1974; JONES 1979; NARCHI \& GABRIELI 1980). A dobra média de P. pectorina é dupla, sendo que a média interna apresenta um grande número de tentáculos ao longo da margem livre é muito semelhante a de C. subrostrata (NARCHI \& GABRIELI 1980), dando uma aparência rendilhada à borda do manto. Estes tentáculos do lado direito e do lado esquerdo se entrosam de tal forma que impedem a entrada de partículas maiores na cavidade palial.

O aparecimento de uma quarta dobra do manto, ou seja, uma dobra adicional nos Veneridae, causou controvérsia quanto a possível origem dessa estrutura (ANSELL 1961; OCKELMAN 1964).

YONGE (1957) e ANSELL (1961) sugeriram que a quarta dobra ou dobra mais interna dos Veneridae seria a terceira dobra, ou seja, a dobra mais interna dos outros bivalves, e que as segunda e terceira dobras corresponderiam à segunda dobra ou dobra mediana, a qual se duplicou (ou se dividiu) mantendo sua função sensorial.

HILLMAN \& SHUSTER (1966), analisando as semelhanças histológicas entre a quarta dobra do manto e outros cortes da extremidade do manto, determinou que a quarta dobra pode se originar de três maneiras: 1) a partir de uma divisão da dobra interna típica; 2) a partir de uma dobra da superfície interna da margem do manto; 3) a partir de uma combinação da superfície interna da margem do manto e da superfície interna da terceira dobra do manto. Acrescentaram, ainda, que a última alternativa parece ser a mais provável.

Observou-se que a atividade ciliar em $P$. pectorina acumulou partículas de carborundum e areia na região da quarta dobra, que envolvidas por muco formaram um fio na borda do manto, semelhante ao que foi registrado por HiLlman (1964) em Mercenaria mercenaria (Linné, 1758). Em P. pectorina não foram observadas costelas adjacentes à quarta dobra. HILLMAN (1964) quando estudou a morfologia da quarta prega da borda do manto de $M$. mercenaria, constatou que ela e uma pequena costela ou orla adjacente, secretam grandes quantidades de muco e substâncias mucóides, que associadas à atividade muscular da dobra e costela parecem ajudar na remoção de detritos e pseudofezes da cavidade do manto.

HILLMAN \& SHUSTER (1966) reconheceram a presença de uma dobra interna em M. mercenaria, Chioninae do Atlântico Setentrional, a qual parece corresponder à quarta dobra de $P$. pectorina. ANSELL (1961) descreveu uma dobra semelhante para alguns venerídeos britânicos, que interpretou como uma forma reduzida da terceira prega ou prega interna dos outros grupos de bivalves. Não atribuiu função alguma para esta dobra interna dos venerídeos, apenas acrescentou que ela se assemelha às encontradas em alguns Tellinoidea (YoNGE 1949), embora em Veneridae elas não formem um canal de rejeição e, portanto, não têm função na distribuição de pseudofezes.

JONES (1979), considerando esta hipótese de HiLlman \& SHUSTER (1966), concluiu que, de acordo com aqueles autores a função sensorial da segunda dobra ou dobra mediana foi assumida por parte da terceira dobra padrão, e que os autores não consideraram o aspecto de que as funções da dobra mediana padrão foram mantidas pela duplicação da mesma nos Veneridae (YONGE 1957; ANSELL 1961). 
SimONE (1994) descreveu em Anodontites trapesialis (Lamarck, 1819) Unionoidea Fleming, 1828 uma dobra adicional que considerou como a quarta dobra do manto. Esta prega é subparalela e distante da borda do manto, iniciando-se no terço anterior e terminando na união dos canais incurrente e excurrente. Aparentemente a proximidade com a prega do lado oposto separaria os fluxos incurrente e excurrente já citados por KELLOGG (1890) para os gêneros Union Philipsson, 1788 e Anodonta Lamarck, 1799. Sendo assim, o aparecimento da quarta dobra do manto, na concepção de YONGE (1957), ANSEll (1961) e HillMAN \& SHUSTER (1966) ocorre sempre na borda do manto, sendo restrita aos Veneroidea Rafinesque, 1815, e não ocorrendo nos Unionoidea.

Protothaca pectorina apresenta a forma dos músculos adutores, retratores do pé e a distribuição de suas fibras muito semelhante à que ocorre em $A$. brasiliana (NARCHI 1972) e C. subrostrata (NARCHI \& GABRIELI 1980). Em P. pectorina também não ocorrem os músculos protratores e elevadores do pé, que é muito semelhante na forma, porém mais desenvolvido nessa espécie.

Em P. pectorina, com em A. brasiliana, T. mactroides (NARCHI 1972) e $C$. subrostrata (NARCHI \& GABRIELI 1980) a disposição dos órgãos na cavidade do manto é semelhante a evidenciada nos Veneridae. Os palpos labiais de $P$. pectorina são grandes como os de C. subrostrata (NARCHI \& GABRIELI 1980), enquanto que os de $A$. brasiliana não são tão desenvolvidos.

Protothaca pectorina apresenta abertura pediosa grande, com em A. brasiliana, T. mactroides (NARCHI 1972) e C. subrostrata (NARCHI \& GABRIELI 1980).

Os ctenídios de $P$. pectorina pertencem ao tipo C(1a) de ATKINS (1937), e demibrânquia interna mais desenvolvida que a externa, com uma extensão supraaxial que varia em tamanho. Os ctenídios dessa espécie assemelham-se aos descritos respectivamente por NARCHI (1972) e NARCHI \& GABRIELI (1980) em A. brasiliana e C. subrostrata.

A diferença mais significativa entre os ctenídios das três espécies é que em $P$. pectorina os filamentos são homorrábdicos e não heterorrábdicos, o que não se verifica na maioria dos Veneridae estudados. Foram observadas ainda algumas diferenças e semelhanças em detalhes de sua estrutura.

RIDEWOOD (1903) deixou claro que nos Veneridae existe a possibilidade de nos ctenídios aparecerem lamelas homorábdicas com o fato de alguns filamentos presentes não se diferenciarem dos restantes: é o que acontece em Tapes aureus mas não em Venus calophylla Philippi, 1836. No entanto, nesta última espécie, a demibrânquia é muito mais pregueada do que em $P$. pectorina. NARCHI (1978) observou na demibrânquia de Donax hanleyanus Philippi, 1847 porções lisas, levemente pregueadas ou fortemente pregueadas, porém sem a presença de filamento principal. As demibrânquias de $P$. pectorina são muito semelhantes às apresentadas nos desenhos de NARCHI (1978) para demibrânquias lisas ou levemente pregueadas de $D$. hanleyanus.

Em $P$. pectorina as demibrânquias são pigmentadas nas extremidades livres, principalmente na demibrânquia interna. NARCHI (1972) e NARCHI \& GABRIELI (1980) não se referiram a qualquer tipo de pigmentação nas demibrânquias de $A$. 
brasiliana e C. subrostrata. Protothaca pectorina possui pregas extremamente rasas em sua região posterior; é lisa na anterior, o que não acontece nas outras duas espécies. A disposição dos filamentos branquiais é semelhante nas três espécies, com os mesmos tipos de cílios, funcionando do mesmo modo: diferem no comprimento, sendo que em $P$. pectorina os cílios látero-frontais e terminais são maiores. A presença de cílios limpadores como encontrados em T. mactroides (NARCHI 1972) demonstra adaptação da espécie a ambiente com partículas grandes em suspensão. Os ctenídios de P. pectorina pertencem ao mesmo tipo dos ctenídios de $C$. subrostrata, ou seja, $\mathrm{C}(1 \mathrm{a})$, enquanto que $A$. brasiliana possui ctenídios do tipo $\mathrm{C}(1)$.

Os Veneridae que apresentam cílios limpadores são os que vivem em ambiente conturbado com partículas grandes em suspensão que podem injuriar os ctenídios. NARCHI $(1972,1978)$ encontrou-os em T. mactroides e $D$. hanleyanus. A presença destes cílios talvez seja devida ao fato da ocorrência de grãos de areia em suspensão na água, uma vez que no substrato em que $P$. pectorina vive existem faixas arenosas subjacentes ao lodo.

Segundo YONGE (1949), nos bivalves que vivem em ambiente lodoso, onde partículas extremamente finas podem ser encontradas na cavidade do manto, existe uma tendência deles apresentarem palpos labiais bem desenvolvidos.

Os palpos de $P$. pectorina são semelhantes aos de $A$. brasiliana e $C$. subrostrata, na estrutura, atividade muscular e correntes ciliares. Apresentam entretanto algumas diferenças.

Em P. pectorina e Veremolpa scabra (Hanley, 1845), como observou NARCHI (1980), os palpos são bem desenvolvidos, enquanto que em A. brasiliana os palpos são pouco desenvolvidos (NARCHI 1972). Em C. subrostrata (NARCHI \& GABRIELI 1980) observou-se que as pregas dos palpos são em menor número e relativamente separadas umas das outras, enquanto que os ctenídios são bem pregueados. Em P. pectorina observou-se que os palpos são muito pregueados e os ctenídios são lisos ou levemente ondulados.

Protothaca pectorina apresenta mais correntes de reaceitação nos palpos do que as que aparecem em A. brasiliana (NARCHI 1972) e C. subrostrata (NARCHI \& GABRIELI 1980).

As correntes ciliares existentes nos palpos de $P$. pectorina são semelhantes às de outros venerídeos, descritos por NARCHI $(1971,1972,1980)$. Isso ocorre também nos Veneracea observados por ANSELL (1961) e em Petricola (Rupellaria) typica (Jonas, 1844) estudado por NARCHI (1974).

Palpos grandes como os de P. pectorina, C. subrostrata e V. scabra são comuns em cavadores de lodo (YONGE 1949), nos quais material muito fino entra na cavidade do manto através da sucção realizada pelo sifão inalante. Apesar de viver no mesmo habitat, onde as águas são calmas e com partículas muito finas em suspensão, $A$. brasiliana não apresenta o mesmo tipo de palpos que as demais.

Os palpos representam uma estrutura de grande adaptabilidade ao meio. Segundo PURCHON (1963), de acordo com o ambiente, as espécies que vivem em habitat mais lodoso têm uma complexidade maior nas correntes de seus palpos, enquanto que as espécies que vivem em habitat com partículas maiores em suspen- 
são possuem palpos menores, com correntes mais simples e menos eficientes na seleção de partículas.

O padrão das correntes ciliares observado na superfície da massa visceral de $P$. pectorina é semelhante ao das espécies de Veneridae estudadas por ANSELL (1961). Os trabalhos de NARCHI (1972) e NARCHI \& GABRIELI (1980), respectivamente com as espécies $A$. brasiliana e C. subrostrata não fazem menção àquelas correntes, mas observou-se em laboratório que são extremamente semelhantes as de P. pectorina.

A superfície do manto de $P$. pectorina apresenta cílios curtos que formam fortes correntes de rejeição em direção à região posterior do animal. As correntes têm direção ventral, sendo mais intensas anteriormente, embora ocorram correntes nítidas na região mediana e bem mais fracas na região posterior. Estas correntes formam próximo à borda do manto uma forte corrente de rejeição em direção posterior. Em A. brasiliana a área posterior apresenta inatividade ciliar (NARCHI 1972). Em P. pectorina existem correntes radiais menores, como em T. mactroides (NARCHI 1972), que dirigem as partículas ventralmente e a área de inatividade ciliar é praticamente inexistente. A orientação das partículas é semelhante à descrita por KELlOGg (1915) para Venus mercenaria (Linné, 1758) e Chione fluctifraga (Sowerby, 1853). Em A. brasiliana (NARCHI 1972) e C. subrostrata (NARCHI \& GABRIELI 1980) as correntes que orientam as partículas também são semelhantes. As partículas sofrem a última triagem quando chegam ao canal alimentar.

O plano geral do sistema digestivo e o aspecto das voltas do intestino de $P$. pectorina são semelhantes aos de A. brasiliana e C. subrostrata, conforme a descrição, respectivamente, de NARCHI (1972) e NARCHI \& GABRIELI (1980), para essas duas últimas espécies.

Algumas diferenças mais significativas foram observadas, tais como a presença de um esôfago longo em $P$. pectorina e a disposição do intestino médio, que variou nas três espécies.

A estrutura geral do canal alimentar e do estômago é muito homogênea nos Veneridae estudados até agora (GRAHAM 1949; PURCHON 1955, 1960, 1987; ANSELl 1961; DiNAMANI 1967; NARCHI 1971, 1972, 1980; JONES 1979; NARCHI \& GABRIELI 1980), sendo que apenas uma ou outra estrutura apresenta alguma modificação.

Considerando os tipos de estômago já estudados por vários autores para os Veneridae, o de $P$. pectorina pertence ao tipo V (PURCHON 1960, 1987) assim como o de $A$. brasiliana e o de C. subrostrata, descrito por NARCHI (1972) e NARCHI \& GABRIELI (1980), respectivamente. Na concepção de PURCHON (1959), o estômago poderia ser usado para uma nova classificação dos Bivalvia. O tipo $\mathrm{V}$ teria se originado do tipo IV, que é mais primitivo.

O sulco na entrada do estômago, que circunda a extremidade proximal do esôfago foi registrado em P. pectorina, confirmando a observação de NARCHI (1972) para $T$. mactroides e A. brasiliana e a de NARCHI \& GABRIELI (1980) para C. subrostrata. JONES (1979) observou da mesma forma aquela estrutura ou trato circular de ANSELL (1961) nos Chioninae estudados por aquele autor. 
No ceco direito em $P$. pectorina desembocam seis dutos do divertículo digestivo como em A. brasiliana (NARCHI 1972) e C. subrostrata (NARCHI \& GABRIELI 1980). O ceco esquerdo recebe oito dutos, diferindo do número das duas últimas espécies, a saber sete em A. brasiliana e cinco em C. subrostrata.

A bolsa esquerda (be) que fica acima do ceco esquerdo (ces), apresenta uma área de triagem (sa6) semelhante a que ocorre em C. subrostrata (NARCHI \& GABRIELI 1980). Em A. brasiliana esta zona de triagem não foi descrita por NARCHI (1972), mas está presente em V. scabra (NARCHI 1980).

O trato de aceitação (ta), descrito por ANSELL (1961) para os Veneridae, foi observado por NARCHI (1972) em A. brasiliana, NARCHI \& GABRIELI (1980) para C. subrostrata. Em P. pectorina observou-se que este trato na região posterior da área de triagem (sa3) é mais desenvolvido que nas espécies acima relacionadas.

É importante citar um caráter típico de $P$. pectorina, que é a coloração pigmentar marrom dentro do estômago, nas pregas das áreas de seleção sa3, sa7, na tiflossole maior e a cor alaranjada característica do capuz dorsal. Essa é a primeira referência de pigmentação e coloração dessas estruturas em Veneridae.

AGRADECIMENTO. Ao Conselho Nacional de Desenvolvimento Cientifico e Tecnológico $\mathrm{CNPq}$ - pelo auxilio financeiro na forma de Bolsa de Produtividade Cientifica, que possibilitou a realização deste trabalho.

\section{REFERÊNCIAS BIBLIOGRÁFICAS}

ALtena, C.O. van R. 1971. On six species of Marine Mollusca from Suriname, four of which are new. Zoöl. Meded. 45: 75-86.

ANSELL, A.O. 1961. The functional morphology of the British species of Veneracea (Eulamellibranchia). Jour. mar. biol. Ass. U.K. 41 (2): 489-517.

AtKINS, D. 1937. On the ciliary mechanism and interelationships of Lamellibranchs. Part III. Types of Lamellibranchs gills and their food currents. Q. Jour. microse. Sci. 79 (N.S.): 371-421.

DALL, W.H. 1902. Synopsis of the family Veneridae and of the North American Recent species. Proc. U.S. nat. Mus. 26: 335-412.

DinAmANI, P. 1967. Variation in the stomach structure of the Bivalvia. Malacologia 5 (2): 225-268.

DOMANESCII, O. 1995. A comparative study of the functional morphology of Semele purpurascens (Gmelin, 1791) and Semele proficua (Pulteney, 1799) (Bivalvia: Semelidae). Veliger 38 (4): 323-342.

Duvst, D.M. 1963. The comparative anatomy of some Lamellibranch siphons. Proc. malc. Soc. Lond. 35 (6): 289-295.

Fischer-PietTe, E.; M. Kf.MPF \& A.M. Testud. 1970. Nouvelles donées sur les Veneridae (Mollusques, Lamellibranches) du Brésil. Bull. Mus. Hist. nat., Paris, 41 (6): 1543-1553.

GoffERGÉ, C.N. 1950. Contribuição à Zoogeografia da Malacofauna do litoral doEstado do Paraná. Archos Mus. Paranaense 8: 221-282.

Graham, A. 1949. The molluscan stomach. Trans. R. Soc. Eding. 61 (3): 737-778.

GrAhAM, V.E. 1955. Sea shore life of British Guiana. In: A biology for the West Indies and British Guiana. London, Mcmillan, VII 308, 1 (3): 1-76.

Hil.man, R.E. 1964. The functional morphology of fourth fold of the mantle of the Northern Quahog Mercenaria mercenaria (L.). Jour. Mitchell Soc. 80: 8-12.

Hillman, R.E. \& C.N. Shuster JR. 1966. A comment on the origin of the fourth fold in the mantle of the quahog, Mercenaria mercenaria. Chesapeake Science 7: 112-113. 
JONES, S.C.C. 1979. Anatomy of Chione cancellata and some other Chionines (Bivalvia: Veneridae). Malacologia 19 (1): 157-199.

KEEN, A.M. 1969. Superfamily Veneracea Rafinesque, 1815, p. 670-690. In: R.C. Moore (Ed.). Treatise on Invertebrate Paleontology. Part B, Bivalvia.

1971. Sea shells of Tropical West America. Stanford, Stanford Univ. Press, 1064p.

KellogG, J.L. 1890. A contribuction to our knowledge of the morphology of Lamellibranchiate mollusks. Bull. U.S. Fish Comission 10: 389-436.

- 1915. Ciliary mechanisms of Lamellibranchs with descriptions of antomy. Jour. Morph. 26 (4): 625-701.

Lamarck, J.B. 1818. Histoire Naturelle des Animaux sans vertébres. Paris, Deterville Libraire, Verdicre Libraire, vol. 5, p. 411-612.

Lange de Morretes, F. 1949. Ensaio de Catálogo dos Moluscos do Brasil. Archos Mus. Paranaense $7(1): 5-216$.

Maury, C.J. 1925. A further contribition to the Paleontology of Trindad (Miocene Horizons). Bull. Amer. Paleont. 10 (42): 7-250.

NARCHI, W. 1971. Struture and adaptation in Transenella tantilla (Gould) and Gemma gemma (Totten) (Bivalvia: Veneridae). Bull. mar. Sci. 21 (4): 866-885.

1972. Comparative study of the functional morphology of Anomalocardia brasiliana (Gmelin, 1791) and Tivela mactroides (Born, 1778) (Bivalvia: Veneridae). Bull. mar. Sci. 22 (3): 643-670.

1974. Aspectos ecológicos e adaptação de alguns bivalves do litoral paulista. Papéis Dep. Zool. São Paulo 29 (19): 237-262.

- 1978. Functional anatomy of Donax hanleyanus Philippi, 1847 (Donacidae-Bivalvia). Bol. Zool. Univ. São Paulo 3: 121-142.

1980. On the biology os Veromolpa scabra (Hanley, 1845) (Bivalvia: Veneridae) from the South China Sea, p. 277-289. In: B. MORTON (Ed.). Proceedings of the First International Worshop on the Malacofauna of Hong Kong and Southern China. Hong Kong, Hong Kong Univ. Press.

NARCHI, W. \& M.A. GABRIELI. 1980. Sobre a anatomia funcional de Chione subrostrata (Lamarck, 1818). Rev. Nordest. Biol. 3 (especial): 25-46.

OCKelmAn, K.W. 1964. Turtonia minuta (Fabricius) a neotenous veneracean bivalve. Ophelia 1: 121-146.

Orbigny, A. 1847. Voyage dans l'Amerique Méridionale pendant 1826-1833. Chez P-Bertrand, Editeur, Zoologie, Paris 5: 1-758.

OWEN, G. 1953. On the bilogy of Glossus humanos (L.) Isocardia cor Lam. Jour. mar. biol. Ass. U.K. 32: 85-106.

Palmer, K.V.W. 1927. The Veneridae of Eastern America, Cenozoic and Recent. Palaeontrogr. Amer. 1 (5): 209-522.

PuRCHON, R.D. 1955. The functional morphology of the rockboring lamellibranch Petricola pholadiformis. Jour. mar. biol. Ass. U.K. 34: 257-278.

- 1959. The stomach in the Eulamellibranchia; stomach type IV. Proc. zool. Soc. Lond. 131: 487-525.

-1960. The stomach in the Eulamellibranchia, stomach types IV and V. Proc. zool. Soc. Lond. 135 (3): 431-489.

-1963. A note on the biology of Egeria radiata Lam. (Bivalvia: Donacidae). Proc. malacol. Soc. Lond. 35 (6): 251-271.

. 1987. The stomach in the Bivalvia. Phil. Trans. R. Soc. Lond. 316 B, 183-276.

Ridewood, W.G. 1903. On the structure of the gills of the Lamellibranchia. Phil. Trans. R. Soc. Lond. 195 B: $147-284$.

Rıos, E.C. 1970. Coastal Brazilian seashells. Rio Grande, Fundação Cidade do Rio Grande, Museu Oceanográfico do Rio Grande, 255p. 
1975. Brazilian marine mollusks iconography. Rio Grande, Fundação Cidade do Rio Grande, Fundação Universidade do Rio Grande, 331p.

- 1985. Seashells of Brazil. Rio Grande, Fundação Cidade do Rio Grande, Fundação Universidade do Rio Grande, Museu Oceanográfico, Rio Grande, 328p.

- 1994. Seashells of Brazil. Rio Grande, Fundação Cidade do Rio Grande, Fundação Universidade do Rio Grande, Museu Oceanográfico "Prof. Eliézer de Carvalho Rios", 368p.

SimONE, L.R.L. DE. 1994. Anatomical Characters and Systematics of Anondotites trapesialis (Lamarck,

1819) from South America (Mollusca, Bivalvia, Unionoida, Muteloidea). Studies on Neotropical Fauna and Environment 29: 169-185.

Stanley, S.M. 1970. Relations of shell form to life habits in the Bivalvia (Mollusca). Mem. geol. Soc. Amer. 125: 296.

STAZEK, C.R. 1963. Synopsis and discussion of the Association of Ctenidia and Labial palps in the bivalved Mollusca. Veliger 6 (2): 91-97.

YoNGE, C.M. 1948. Formation of siphons in Lamellibranchia. Nature 161 (4084): 198-199. . 1949. On the structure and adaptation of the Tellinacea deposit-feeding Eulamellibranchia.

Phil. Trans. R. Soc. Lond. 234: 29-76.

. 1957. Mantle fusion in the Lamellibranchia. Pubbl. Staz. zool. Napoli 29: 151-171.

1982. Mantle margins with a revision of siphonal types in the Bivalvia. Jour. Moll. Studies

48: $102-103$

Recebido em 30.XI.1998; aceito em 13.XII.2000. 